\title{
Public Utility Pricing and Capacity Choice with Stochastic Demand
}

\author{
Laurent David* $\quad$ Michel Le Breton ${ }^{\dagger} \quad$ Olivier Merillon ${ }^{\ddagger}$
}

August 2007

\begin{abstract}
This paper is in the continuation of our previous paper which has highlighted the fundamental and pioneering contributions made by S.C. Kolm in the area of traditional public economics. In this second paper, we focus on the implications of these general ideas in the case of a market environment characterized by demand uncertainty and derive some practical pricing rules to regulate the access to pipeline transportation capacities.
\end{abstract}

Keywords: Public Utility Pricing, Regulation, Stochastic Demand.

\section{JEL Classification Numbers:}

*Gaz de France-R\&D Division- Economics and Sociology Unit.

†Toulouse School of Economics, Gremaq and Idei.

$\ddagger$ Gaz de France-R\&D Division- Economics and Sociology Unit. 


\section{Introduction}

This paper is in the continuation of our other paper (David, Le Breton and Merillon (2007b)) devoted to an exploration of Kolm's contributions to theoretical public economics from a historical perspective. In contrast to the previous one which was rather general in terms of coverage of topics and specifications, it concentrates on the implications of a specific aspect of the economic environment often encountered by public sector managers and regulators : the uncertainty attached to the demand of the $\operatorname{good}(\mathrm{s})$ and service(s) produced by this public firm or administration. Following an early paper of Boiteux, Kolm has made important contributions to that topic. This is (we think) a perfect illustration of the themes and ideas discussed in the first paper. It is clearly a real practical problem met by most public utilities with more or less acuity and it is not obvious at all to adjust the cost marginal principle to that situation mostly because the root of the uncertainty on demand (not the uncertainty on primitives like preferences, of course) lies in the impossibility of organizing a complete set of Arrow-Debreu markets. These "institutional" limits on trade opportunities and in particular the impossibility to achieve efficient risk sharing (i.e. equality of the marginal rates of substitution of income across agents ans states of nature) give rise to a second best environment where the determination of optimal public prices is likely to be sensitive to the details of the contractual environment which is ultimately considered. Indeed as far as we know, there are no very general results on second-best rules when the second best nature arises from incomplete markets. The authors of this paper have examined practical policy problems raised by the deregulation process of energy markets, with a particular attention to natural gas. They argued that the framework of a public utility facing individual stochastic demands is very much appropriate in the case of the public utility in charge of the transportation of natural gas in France (Gaz de France Réseau Transport). This utility is under the authority and control of the French regulator in charge of these issues : the "Commission de Régulation de l'Energie" (CRE in short). The derivation of "optimal" rules for investment and pricing is not a straightforward exercice. The regulator adopted a number of resolutions which have reached, sometimes, a high degree of sophistication and complexity. In our work, we investigate the theoretical foundations of these rules. We, modestly, follow the tradition ${ }^{1}$ of Kolm and these "ingénieurs économistes" by tying to make best use of microeconomic theory to help in formulating some of the current main pricing and other issues faced by public utilities and in evaluating the regulatory policies which are

\footnotetext{
${ }^{1}$ Two of the authors are employees of the reseach division of Gaz de France while the other one is an employee of a French university
} 
implemented to enhance efficiency.

In the previous paper, we have discussed optimal departures from marginal cost pricing to accomodate various second best constraints but the various uncertainties faced by the public utility were not taken into consideration ${ }^{2}$. Such extension is worthy as such is the world that most utilities find themselves in. It should be important however to distinguish these randomness from some other features describing the variability of demand. Indeed, as pointed out by Drèze (1964) "Short-run fluctuations in demand occur frequently in random as well as in periodic patterns. In the case of a non-storable commodity, the pricing problem raised by random fluctuations in demand is quite different from the problem of peak-load pricing. One might expect that when the life of the equipment is long relative to the period over which demand exhibits significant fluctuations (around a known average), investment decisions would be guided by the same principles, no matter whether the fluctuations are random or periodic. As we shall see, this is not always so. As for pricing decisions, the basic difference is the following : peak load pricing calls for a known periodic schedule of prices, whereas pricing at short-run marginal costs under stochastic demand conditions would call for stochastic price variations".

These considerations lead to the following fundamental question : why is it the case that the public utility is confronted to a stochastic demand ? In these introductory lines, we would like to argue that the origin of this situation lies in the fact that there is not a complete set of Arrow-Debreu markets to deal with the fundamental uncertainties on demand and supply. Remember that, according to Guesnerie (1975), this is one of the main reason (out of three) for being in a second-best environment. To explain in more details this point and what is subsequently done in this section, we consider a simplified temporal structure, as in Green, Mas-Colell and Whinston (1995)'s textbook, in their treatment of equilibrium under uncertainty. We consider two periods : period 0 (ex ante) and period 1(ex post) and uncertainty is described through a set of states of the world $\Omega$ (where a state of the world $\omega \in \Omega$ is understood as a complete description of a possible outcome of uncertainty). This uncertainty is resolved ex post. The public utility produces several physical goods (as it has been assumed to be possibly multiproduct) and also use several physical goods as inputs. Consider the situation of this public utility and its clients at time 0 . The addition

\footnotetext{
${ }^{2}$ As noted for instance by Sherman and Visscher (1978)Ways to depart from marginal cost pricing to increase revenue and yet minimize the resulting misallocation of resources are well-accepted members of a growing family of constrained welfare-maximizing prescriptions. An important application is found in public utility pricing, where optimal peak and off-peak pricing arrangements has been modified as needed to admit second best characteristics. Second best two-part tariff schemes provide another example of pricing rules modified to satisgy budget constraints. But in all these examples, demand is assumed known with certainty. Little attention has been given to second best solutions when demand has a random element".
} 
of uncertainty creates a set of Arrow-Debreu contingent commodities : a commodity here consists in the physical description of the output or input used by the public utility together with the contingency (state of the world) under which delivery takes place ${ }^{3}$. From the point of view of the public utility, a decision is then a state-contingent production plan specifying how much of each good or service is produced and how much of each unput is used in each contingency. From the point of view of a client, a decision is a state-contingent consumption plan describing how much of each good or service is purchased for each contingency. Market completeness refers to the situation where a market is opened for each contingent commodity. To each such commodity is attached a price and clients optimize in this sophisticated market environment : each of these clients would sign a contractual agreement with the public utility with ex ante payments and contingent delivery. This presentation of markets arrangements where all trade takes place simultaneouly and before the uncertainty is resolved is hardly realistic but we can reinterpret it by means of a trading process that actually unfold through time. For the time being, we simply note that the uncertainty has disappeared from the perspective of the public utility. It has collected a certain amount of money ex ante from its clients and paid a certain amount of money to its own suppliers. All the conceivable risks of some relevance for this public utility and his clients have been insured through this set of markets. The (Arrow-Debreu) equilibrium resulting from a competitive price taking behavior of the clients together with appropriate marginal cost pricing rules for the utility are optimal from a first-best perspective. Note finally, that in this ideal market configuration, there is no need to open ex post the markets for the physical goods and services i.e. there is no justification for spots markets.

In reality, this ideal market environment rarely prevails. Many conceivable ArrowDebreu markets for contingent commodities do not exist ${ }^{4}$. Kolm (1971a) makes that point explicitely $^{5}$ : "Sur l'analyse et la pratique de l'économie, l'incertitude a un impact profond. L'extrème rareté des marchés à terme et conditionnels, l'incertitude des prix futurs, sont l'une des plus sérieuses limitations du régime de libre entreprise et de libre-échange. Mais des plans remplacant ce système ne se heurtent pas moins à l'incertitude sur les facteurs qui

\footnotetext{
${ }^{3}$ Precisely, a contingent commodity is a good for which the effective delivery is subject to the realization of a particular (verifiable) state of the world (contingency,....).

${ }^{4}$ It is now well accepted that, in many circumstances, the organization of such markets as well as the design of sophisticated contracts between parties involved in such transactions is simply impossible as the transactional costs attached to these hypothetical trading arrangements would be prohibitive. We will come back several times on that point when discussing the second-best market environments which are conceivable as responses to the fact that markets are incomplete..

${ }^{5}$ This has been noted also by many authors working on public utility pricing. For instance, Coate and Panzar writes :" Such is the world that most utilities find themselves in, since, in general, neither 'spot pricing" nor state-contingent contracts are possible mechanisms for the sale of their (nonstorable) services".
} 
détermineraient ces prix. L'effet de cette ignorance est d'autant plus grave que les décisions prises hypothèquent davantage un avenir plus lointain. Il est donc en particulier important pour les activités capitalistiques à capital illiquide....les incertitudes qui les concernent au premier chef sont celles de leurs coûts et, souvent plus encore, de leurs demandes, futurs. Les principales décisions qui en sont affectées sont les choix des investissements et des tarifs ou prix. La situation financière de ces organismes, et toutes ses conséquences institutionnelles, en sont donc touchées...". In such market environments, some transactions are unfeasible and that some gains from trade are not going to be exploited. If we consider all the physical goods for a delivery at a specific time (say here $t=1$ ), we have to defined what is the set of markets or contracts that are feasible and how these exchanges are regulated through prices and rationing. Spot markets corresponding to buying and selling the good or service at time $t=1$ once the uncertainties are resolved are very often active in contrast to the first-best theory recommendation. In addition, more or less complicated contractual arrangements are likely to be added at the ex ante stage. For instance, a client may sign a forward contract where an immediate payment is made for an ex post delivery of some quantity of the good, depending sometimes upon some contingencies. In this world of incomplete markets, the public utility as well as the clients cannot eliminate uncertainty. This implies that they will have to form expectations about all the variables which are relevant in their decision process. For instance, if the prices are flexible on the spot markets ${ }^{6}$, clients will form expectations about these prices if these arrangements compete with some ex ante alternative contracts and the public utility will do the same to buy ex ante the appropriate amounts of inputs. If prices are rigid and adjustments are made through some form of rationing, then again it is necessary, for all actors, to anticipate the outcomes of these spot markets. This mixed situation has some analogies with the simple temporal setting tyically used to model a situation where in addition to spot transactions, we have also some asset markets. Through these markets, the participants can proceed to the exchange of risks among themselves within the limits permitted by the degree of openess. Economies with incomplete markets display complicated features from the point of view of their welfare properties ${ }^{7}$. For instance, it can well be the case that adding a market to an existing set of markets does not necessarily improve welfare or that a public policy which was diregarded on the basis of first-best considerations

\footnotetext{
${ }^{6}$ As demonstrated by Polemarchakis $(1979$, in these settings involving trade under uncertainty it may be preferable in the absence of markets for contingent commodities, for prices to be regulated and for markets to be cleared through quantity rationing, as opposed to prices being allowed to fluctualte in response to the contingency realized.

${ }^{7}$ As pointed out by Diamond (1980) : "Economies with incomplete markets can have surprising welfare properties. These examples, or counter-examples, bring out the need for further analysis of public policies in the presence of uncertainty and incomplete markets."
} 
becomes valuable. In what follows, we are going to investigate some of these market environments. The selection is based upon the fact that these settings are useful benchmarks from where it is useful to start and (or) represent actual institutions or institutional reform proposals to reorganize existing markets.

A first important benchmark is the case where the set of markets consists exclusively of spot markets. Two important natural benchmarks arise. Either the price is unregulated, and then expost the price is determined to match demand and supply. Or the price is regulated and fixed (ex ante) and then (ex post) some form of rationing may be needed to eliminate excess demand or supply. If some ex ante transactional opportunities are opened on the demand side, then, clients of the public utility do nothave much to do except to wait. In contrast, it is useful for the public utility to forecast the future in particular the stochastic demand in order to buy (ex ante) the relevant optimal amounts of some of the inputs. In what follows, we will often assume that that there is a unique such input : it may receive several alternative interpretations and will correspond to a capacity limit on the aggregate quantity of the good/service that can be delivered in the second period. Given the anticipated behavioral response of the clients to prices, the public utility will be able to evaluate the physical, financial and welfare consequences of any supply policy if prices are rigid or any supply and pricing policy if prices are flexible. On this Drèze (1964) writes ${ }^{8}$ "Stochastic short-run price variations are frequently ruled out on economic, administrative or legal grounds, and such has been almost invariably been the case in the public utilities field. The combination of short-run price rigidity and short-run fluctuations in demand must then result in a combination of (1) some form of demand rationing; and (2) short-run fluctuations in ouput, to be met either by overloading a plant of flexible capacity or by building an adequate safety margin into a plant of fixed capacity. Both of these consequences are costly either to the consumers or to the producers. Whenever consumers can reduce the amplitude of the short-run random fluctuations of their demand, it would obviously be desirable that

\footnotetext{
${ }^{8}$ Drèze also writes that "a satisfactory answer to that question is still missing, for lack of a workable extension to uncertainty situations of the theories of efficiency and Pareto optimality. Such extension would indeed be needed in order to specify the kind of market prices that could bring about an efficient allocation of resources". We presume that Drèze has in mind (quite ahead of his time) a complete set of markets. Let us just mention that it is quite fascinating to learn (as reported in Drèze's footnote 73 ) that during a workshop held in Paris in 1953, discussions around these questions and related ones, inspired by Boiteux (1951)'s seminal contribution, that will be exposed later in this section, took place between Allais, de Fineti, Kreweras, Marchack, Wold and Boiteux himself. Boiteux was suggesting that each customer might specify with what probability he expects his demand to be met, and what loss would result to him from lack of service; the producer would quote his price as a function of both the probability of service he is willing to guarantee and the penalty he would pay in case of shortage. Interestingly enough Drèze writes "Why a public utility should sell insurance as well as electricity is not altogether clear to me".
} 
the price structure induce them to do so. The question thus arises : Can some marginal cost (or welfare loss) be attached to the random variations of an individual consumer's demand ? If so, can a non-stochastic form of price discrimination reflect the marginal cost ?"

In this paper, we will not examine "pure" spot pricing i.e. the market environment consisting exclusively of spot markets where prices adjust until supply and demand are equal. Instead, as suggested by Drèze above, we will consider situations where prices are regulated (ex ante) by the public utility. The menu of contractual arrangements may offer either a narrow or a rich set spectrum of trading opportunities. The simplest case is the situation where no trade opportunity is opened ex ante : the public utility commits to a price and sells its product to that price (ending up in shortage, if the planned capacity is insufficient or sufficient but ineffective due to stochastic shocks, or if the demand is high as the result, for instance, of adverse weather conditions). Sophisticated arrangements offered ex ante to clients consumers will also be discussed. For instance, if the product is truly multidimensional (this happens, for instance, when the consumption of the client over the billing period is differentiated according to a partition of the period into subperiods), a contract may consist of an ex ante commitment by the public utility on a price paid for each unit really consumed (depending possibly upon the subperiod), a price paid for each unit demanded ( where demand can be interpreted for instance either as a binding physical upper bound upon consumption or an indication of the maximal ex post consumption conceivable from the perspective of the client). A client may also be offered a forward contract to which is attached a specific regulated price different from the price that he will pay if he buys ex post. Different forms of contingent contracts can also be considered. For instance, in 1985, E.DF decided to propose to its large customers contracts stipulating the number of days (actually 22 days) when peak-load prices will be charged, but leaving open the actual dates which are announced by EDF on short notice, on the basis of prevailing conditions. As noted by Drèze (1995), "From a theoretical point of view, these developments correspond to state-contingent pricing, with an implicit insurance contract limiting the frequency of peak prices....However, I am not aware of a theoretical analysis validating precisely that arrangement, as opposed to alternative second-best candidates". Another form of contingent forward delivery contracts, priority service (Chao and Wilson (1987)), specifies the customer's service order of priority : in each contingency, the public utility rations supplies by serving customers in order of their selected priorities until the supply is exhausted or all customers are served. Other types of contractual arrangements have been discussed by theorists and practitionners ${ }^{9}$ but as noted by Drèze (1995) "These analyses are still in infancy : the papers that I know do partial

\footnotetext{
${ }^{9}$ See for instance Spulber (1992 a,b) and Wilson (1991) for more theory and examples.
} 
equilibrium analysis under assumptions of risk neutrality. Some day, these papers will be viewed as early illustrations of a general equilibrium analysis that includes uncertainty and incomplete markets". Kolm (1971a $)^{10}$ offers a very insighful classification of tariffs under the heading "Taxonomie de la Tarification de l'Incertitude"; he provides a comparison of the variety of pricing environments that could be (or are) considered/used when demand is stochastic. He writes in particular "Il est intéressant de noter que la nature du sujet dont la connaissance est entachée de l'incertitude considérée (notamment le service ou tel usager) n'a pas d'importance pour décrire la logique de la tarification dans tous les cas où il suffit pour cela de consideérer des services contingents, c'est à dire liès dans leur définition à des éventualités... Les objets de la tarification sont les quantités $q_{j}^{i}$ du service consommées par les usagers $i$ dans les éventualités $j$. Un tarif fonctionnel présenté à l'usager $i$ est une fonction $T^{i}$ de ces quantités pour ce $i$, représentant une somme qu'il doit payer s'il choisit cette consommation. Mais cette tarification peut s'effectuer de différentes manières....." . He discusses nine different schemes. The first one is simply an extension of a complete set of markets à la Arrow-Debreu allowing for personalized and non-linear prices and the three following one are variants of these schemes. The second one forbids ex ante sales : the effective payment takes place a posteriori once the real consumption $q_{j}^{i}$ is known but the functions $T_{j}^{i}$ can be defined a priori. The fifth introduces the possibility of purchasing a specific quantity or an upper bound $\xi^{i}$ on that quantity regardless of the contingency that will prevail; the tariff is then a function $T^{i 11}$.

Within these various market environments, the theoretical and practical literature on public utilities has explored the principles and rules to plan optimally investments in capacity. Indeed, ex ante, the public utility has to decide upon the level of different equipments that will determine the capacity possibilities and more generally the costs to meet the different possible realizations of demand. Given the multiproduct status of the public utility which arises from qualitative as well as temporal, locational, and contingent characteristics, the capacity(ies) is(are) used in the production of several (if not all) the products. The choice of these joint inputs is a key decision. As pointed out by Kolm (1970) : "Un de nos intérêts essentiels sera de déterminer le choix optimal entre les coûts qui servent à la production de plusieurs variétés, qui leur sont communs, et d'autres qui s'attachent spécifiquement à chacune de celles-ci........Dans l'application du modèle à l'incertitude, un coût commun est un coût choisi ante, avant que la demande soit connue, et un coût de production spécifique est un coût choisi ex post en connaissance de la demande à servir....". Once these decisions have

\footnotetext{
${ }^{10}$ In chapter 19.

${ }^{11}$ We refer the reader to Kolm for a complete presentation of these schemes.
} 
been made, the situation (ex post) can be unsatisfactory either because there is an excess capacity $^{12}$ at the given price or instead because there is an excess demand imposing some shortage on customers. Both outcomes are socially costly and it is therefore important to use all the conceivable instruments to proceed in an optimal planning capacity. In that respect, all price signals indicating to clients the costs of their decisions can help. In what follows, we will assume, for the sake of simplicity, that the public utility produces a single physical output and that the capacity is described by a single real number $Z$ which will represent an upper bound on production in the short run. We will further assume that operating and capacity costs are linear; the description of the short-run total cost is provided by equation ()$^{13}$. In any case, the existence of excess capacity should not be interpreted as the sign of a poor management but instead as the optimal response by the public utility to the stochastic demand given the constraints on its pricing instruments. Boiteux (1951) provides a very insightful discussion of this issue after decomposing the demand into three components, each requiring its own pricing treatment. He presents as follows the three rationales for keeping excess capacities : " Ces assertions nous paraissent reposer sur un certain nombre de confusions. Différentes raisons peuvent motiver des capacités de production excédentaires.... Il serait absurde d'en conclure que le tarif de pointe doit être calculé comme si elle constituait une capacité de production systématiquement excédentaire. Nous avons, au cours de cette rapide analyse des régimes de la demande, décelé trois raisons pour lesquelles des capacités de production parfaitement adaptées à la demande peuvent apparaître comme excédentaires et justifier un coût marginal éventuellement faible :

- périodicité de la demande rendant excédentaires, hors-pointe, les investissements nécessités par la pointe,

- trend de la demande justifiant des investissements provisoirement excédentaires, soit en attendant une expansion ultérieure de la consommation, soit en attendant la disparition naturelle d'investissements qu'une régression de la demande a rendu excédentaires,

- aléas de la demande nécessitant des marges de sécurité qui, de par leur fonction même, ne sont qu'exceptionnellement utilisées à plein."

Thepaper is is organized as follows. In a first section, we will present some of the main contributions from the American literature on public utility pricing and capacity choice

\footnotetext{
${ }^{12}$ The notion of capacity refers to the limit case where there is a tight upper bound on production. More generally, it could consist of a park of heterogeneous equipments described by their respective sizes and capacities (see for instance Oren, Smith and Wilson (1985) and Wilson (1991).

${ }^{13}$ This model ignores many difficulties, on top of which, economies of scale. However, we think that this "pedestrian approach" (this expression is borrowed from Drèze (1964)) is rich enough and an excellent start to formulate some basic questions. Note also that we will mostly focus on capacity pricing as the allocation of operating (running) costs is obvious under our linear assumption.
} 
when the demand is stochastic but not decomposed into individual stochastic demands. Then, in a second section, we will discuss the seminal contribution of Boiteux where the same questions are formulated in a setting where, instead of being pooled into an aggregate demand, the customers can be differentiated according to the (some) parameters of their stochastic demand. In a third section, we will move to the contribution of Kolm which consists mostly of a number of important extensions of Boiteux's model. In a fourth section, we will explain how the Boiteux-Kolm prices are related to a common pricing practice known as Hopkinson rate. Finally, in a last section, we will offer a brief description of our own recent work mostly motivated by some proposals made by the French regulator to price the access to the natural gas transportation network.

\section{Aggregate Stochastic Demand}

Before returning to the "French" approach to this question in the next subsections, we first examined how the problem was approached in the U.S. literature and what conclusions have been derived by these authors. The two approaches are quite distinct from each other on many grounds on top of which the modeling of demand side of the market. The U.S. authors $^{14}$ does not take into consideration the profile of individual stochastic demands but simply the aggregate stochastic demand; this may be viewed as an informational assumption on the public utility. The first seminal contribution to this area is due to Brown and Johnson (1969). They consider the case of a public utility which has to determine its capacity $Z$ and a vector of prices $p=\left(p_{1}, \ldots \ldots, p_{t}, \ldots, p_{T}\right)$ for $T$ consecutive periods of equal duration. These periods correspond typically to the time partionning of of a basic time period in order to deal with peak load issues. We denote by $q_{t}\left(p_{t}, u_{t}\right)$ the aggregate demand for period $t$, where $u_{t}$ is a continuous random variable described by the density $f_{t}\left(u_{t}\right)$.

For the sake of simplification in the presentation, we assume the following multiplicative functional form :

$$
q_{t}\left(p_{t}, u_{t}\right)=x_{t}\left(p_{t}\right) u_{t}
$$

where $x_{t}\left(p_{t}\right)$ denotes the mean demand in period $t$, i.e. :

$$
\int_{0}^{\infty} u_{t} f_{t}\left(u_{t}\right) d u_{t}=1
$$

If we make the extra assumption that the mean demand $X_{t}$ is linear with respect to $p_{t}$, we obtain the situation depicted on figure 1 where it is represented for three realizations of $u_{t}: \underline{u}_{t} \leq 1 \leq \bar{u}_{t}$.

\footnotetext{
${ }^{14} \mathrm{~A}$ nice exposition is provided in Berg and Tschirthart (1988).
} 
Figure 1: Linear Demand Function

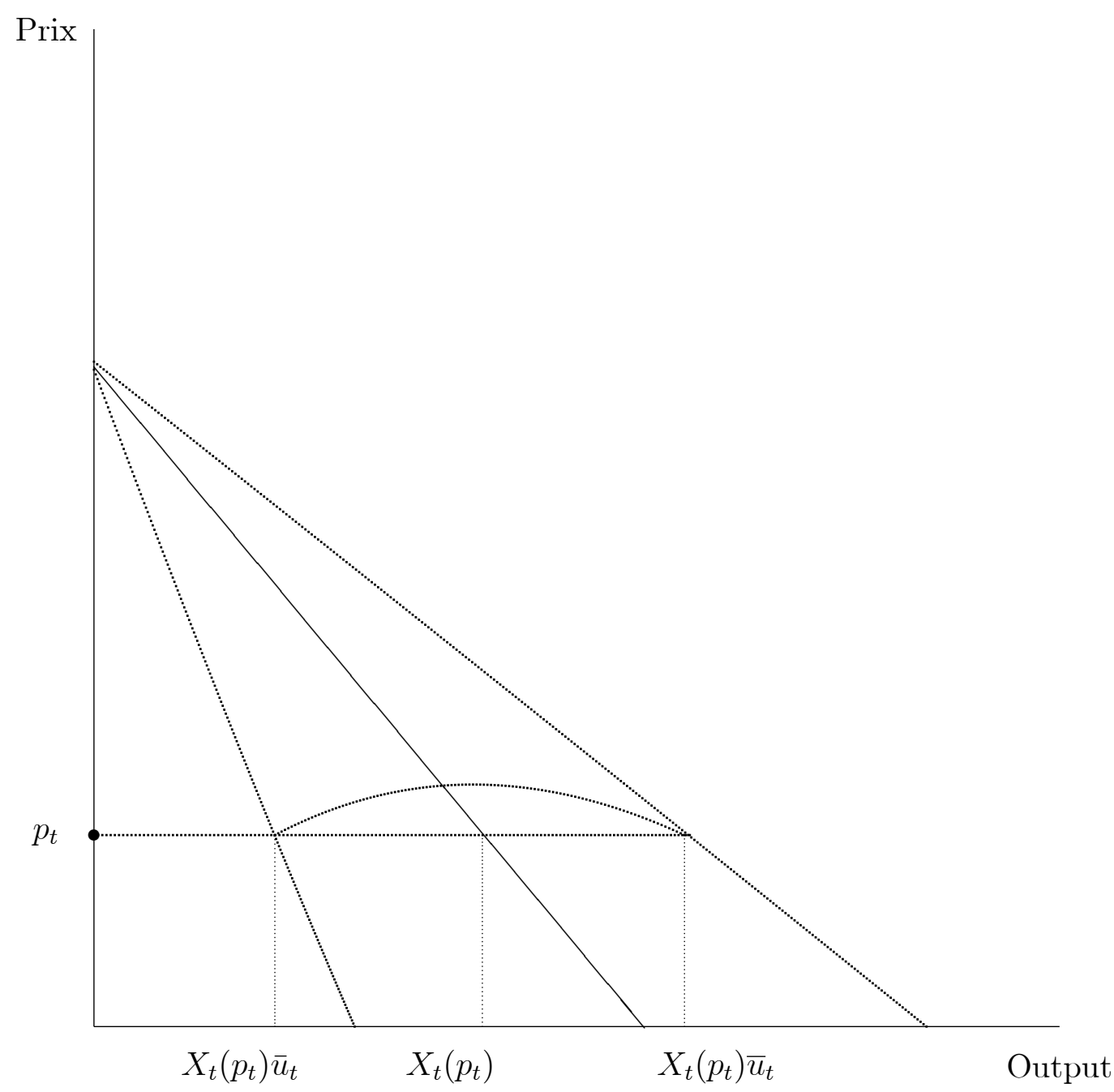

Since the production capacity is decighed Before the resolution of uncertainty, high realizations of $u_{t}$ leads to a situation of rationing. On figure 2 , we have represented a situation of excess demand (attached to the realization $\overline{u_{t}}$ ). If we assume that the rationing is efficient, the loss in aggregate surplus resulting from the rationing $X_{t}\left(p_{t}\right) \bar{u}_{t}-Z$ is measured by the area of the triangle $L$.

Figure 2: Aggregate Surplus Loss 


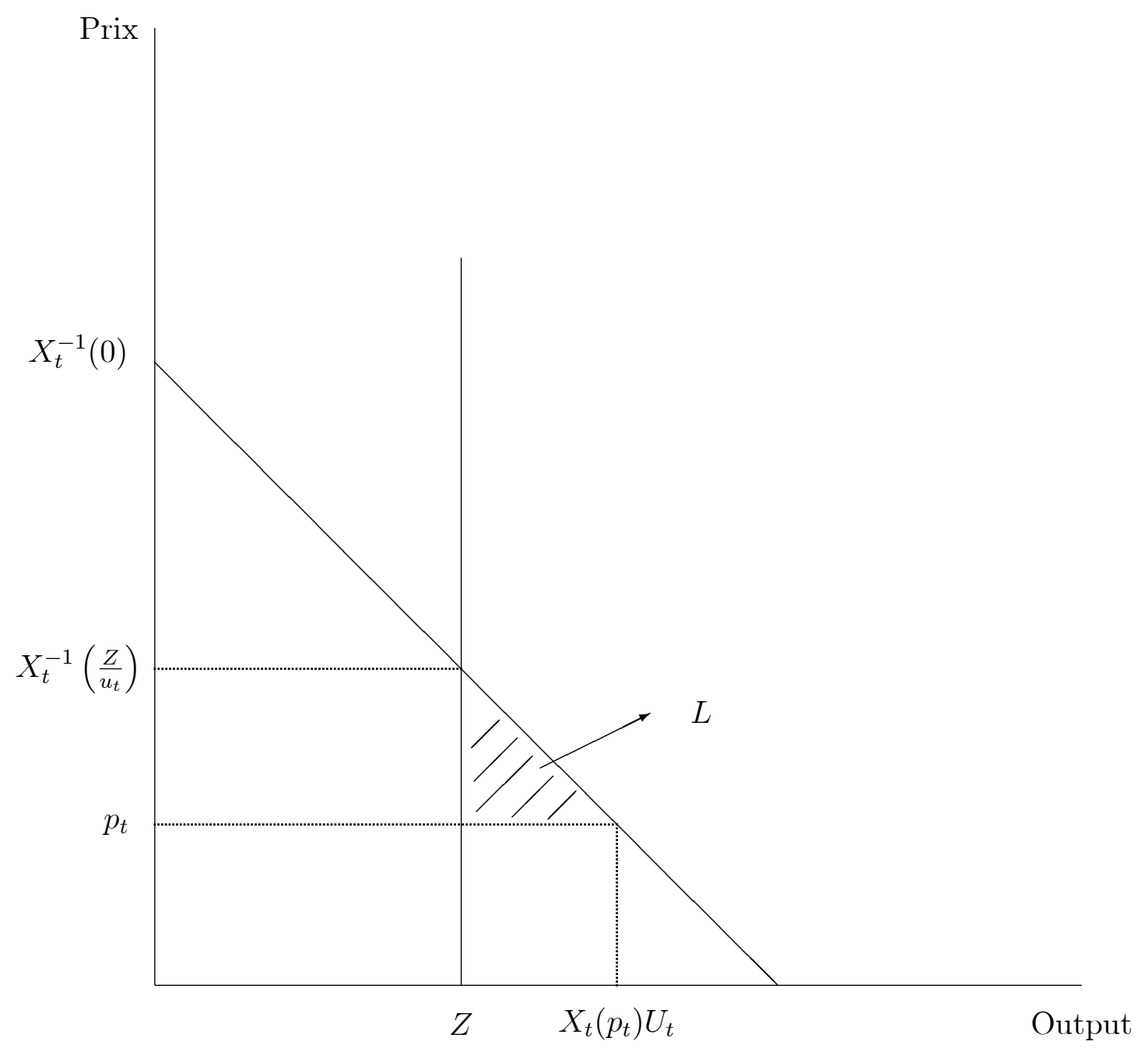

We assume that the objective of thègragulator if the maximization of the expected net social surplus $E(W)$ :

$$
E(W)=E(S-L)+E(R)-E(C)
$$

where $S, R$ and $C$ denote respectively the aggregate consumer surplus, the revenues and the costs of the public utility. For the specification of cost and demand functions considered here, we obtain :

$$
\begin{gathered}
E(S)=\sum_{t=1}^{T}\left[\int_{0}^{\infty} f_{t}\left(u_{t}\right) \int_{p_{t}}^{X_{t}^{-1}(0)} x_{t}(v) u_{t} d v d u_{t}\right] \\
E(L)=\sum_{t=1}^{T}\left[\int_{\overline{x_{t}\left(p_{t}\right)}}^{\infty} f_{t}\left(u_{t}\right) \int_{p_{t}}^{x_{t}^{-1}\left(\frac{z}{u_{t}}\right)}\left(x_{t}(v) u_{t}-z\right) d v d u_{t}\right] \\
E(R)=\sum_{t=1}^{T}\left[\int_{0}^{\frac{z}{x_{t}\left(p_{t}\right)}} f_{t}\left(u_{t}\right) x_{t}\left(p_{t}\right) u_{t} p_{t} d u_{t}+\int_{\frac{z}{x_{t}\left(p_{t}\right)}}^{\infty} f_{t}\left(u_{t}\right) z u_{t} p_{t} d u_{t}\right]
\end{gathered}
$$




$$
E(C)=\sum_{t=1}^{T}\left[\int_{0}^{\frac{z}{x_{t}\left(p_{t}\right)}} f_{t}\left(u_{t}\right) x_{t}\left(p_{t}\right) u_{t} b d u_{t}+\int_{\frac{z}{x_{t}\left(p_{t}\right)}}^{\infty} f_{t}\left(u_{t}\right) z u_{t} b d u_{t}\right]+\beta z
$$

Maximization with respect to $p$ and $Z$ leads to the following solution :

$$
p_{t}^{*}=b \text { pour tout } t=1, \ldots, T
$$

and

$$
z^{*}>\underset{1 \leq t \leq T}{\operatorname{Sup}} x_{t}(b+\beta)
$$

The first and striking important conclusion is that the price in every period should be equal to the short-run (i.e. operating) marginal cost, in sharp contrast with the optimal pricing in the case of a riskless deterministic demand. This sounds like an important argument in defense of the American version of marginal cost pricing and the intuition underlying the result is simple. Consider a price larger than the short-run marginal cost. Either the capacity constraint is not bidding and then reducing the price is a social improvement. Or the capacity constraint is bidding and then reducing the price leaves the situation inchanged as it has been assumed that rationing was efficient. The second conclusionis that the capacity is larger than the capacity selected in the riskless model : the peak demand when the price is equal to the long-run marginal cost.

Although it is tempting to do so, it would be misleading to attribute the primary responsability for their conclusions to the random element in the demand. There are several features of the model which.

Consider first the assumption of efficient rationing. This assumption is not easy to defend here as we have adopted an aggregate perspective and the informations needed to organize efficiently the rationing of a fixed output are individual and private. The design of such procedure issocially costly. From a more positive perspective, we could explore alternative rationing schemes. Visscher (1973) has demonstrated that if instead we suppse instead that service is offered first to those claimants with the lowest wiligness to pay, then the optimal price is equal to the long-term marginal cost and the optimal capacity can be less than the optimal capacity in the riskless case. Similarly, in the more tenable assumption of purely random rationing, the optimal price is now somewhere in between the two marginal costs and the optimal capacity can as before be smaller than the riskless optimal one.

The second aspect of the model which deserves some further analysis is the ex ante (instead of ex post) treatment of the events of large excess demands. In the Brown and 
Johnson's formulation, there is no constraint on the reliability of the system which can be evaluated (for instance) by the probability of the event "the aggregate demand is larger than the available capacity" 15 . When the public utility provides goods considered to be necessities, this may be problematic. There are many different ways to introduce constraints that the regulator will take into consideration to ensure a reasonable reliability.

For instance, we can impose that :

$$
P\left[x_{t}\left(p_{t}\right) u_{t} \leq z\right] \geq \rho_{t} \text { pour tout } t=1, \ldots, T
$$

where the thresholds $\rho_{t}$ are exogenous. In such case, the optimal prices maximize

$$
E(W)+\sum_{t=1}^{T} \gamma_{t}\left[\int_{0}^{\frac{z}{x_{t}\left(p_{t}\right)}} f_{t}\left(u_{t}\right) d u_{t}-\rho_{t}\right]
$$

where $\gamma_{t}$ is the lagrange multiplier attached to the liability constraint for period $t$. Meyer (1975) was among the first to follow that road. He obtains the following optimal prices:

$$
p_{t}^{*}=b+\gamma_{t} \frac{\theta_{t} f\left(\theta_{t}\right)}{x_{t}\left(p_{t}^{*}\right)\left[1-I_{t}\right]},
$$

where

$$
\theta_{t} \equiv \frac{z}{x_{t}\left(p_{t}^{*}\right)} \quad \text { and } \quad I_{t} \equiv \int_{\frac{z}{x_{t}\left(p_{t}^{*}\right)}}^{\infty} u_{t} f_{t}\left(u_{t}\right) d u_{t} .
$$

Optimal prices are now larger than those of Brown and Johnson. In fact there are two ways to meet the reliability constraint : to built a larger capacity or to increase the price. Meyer's prices trade between the two methods. The exact combination will depend upon the parameters of the problem on top of which the marginal capacity cost $\beta$ which influence the value of the prices through the value of the lagrange multipliers.

The third aspect of the Brown and Johnson's model subject to criticism is the fact that the demand isassumed to be independent of the reliability of service. This unrealsitic assumption needs to be recognized as a reliable product is certainly of higher quality than an reliable product. This is important ex ante as the level of reliability will influence the decision to make (or not) some specific investments in durables or to look for commodities which are closed substitutes. Most of the authors consider directly a reduced form of that influence reflected into the aggregate mean demand :

$$
x_{t}\left(p_{t}, \rho_{t}\right)
$$

where $\rho_{t}$ denotes the level of reliability announced by the public utility .

\footnotetext{
${ }^{15}$ We could instead introduce direct penalty costs of excess demand like in Crew and Kleindorfer (1978).
} 
The optimal prices are derived from the maximization of $E(W)$ under the following consistency constraints.

$$
\rho_{t} \leq P\left[x_{t}\left(p_{t}, \rho_{t}\right) u_{t} \leq z\right]
$$

i.e. the announced risks are never larger than the "real" risks, as experimented by the customers. The prices have qualitative features similar to those of Meyer's.

To the best of our knowledge, only Rees(1980) and Coate et Panzar (1989) have provided a structural model to explain why reliability is important and how it enters into the welfare and then into the demand of the customers which could be either households or private firms. To ease the following discussion, let us disregard the seasonal component to focus exclusively on the random component, i.e. we assume that $T=1$. Coate and Panzar provide a model where the uncertainty is on the supply side. The main added value of their analysis is to assume that the demand behavior integrates reliability through rational expectations based on the price and capacity decisions of the public utility : to each policy $(p, z)$ corresponds a unique level of liability $\rho=\rho(p, z)$ meeting the rational expectations test. The optimal price then satisfies

$$
p^{*}=b+\beta\left(\frac{z}{(1-\rho) x\left(p^{*}, \rho\right)}\right) .
$$

It should be noted that this optimal price corresponds to the marginal cost without degrading the quality of service. The price paid must equal marginal operating cost plus the cost of adding enough capacity to serve an additional unit of demand without increasing the probability of curtailment. The additional requirement of capacity required is greater than one unit, because to add only one unit would clearly reduce the reliability of the system. It follows that the optimal price exceeds the long-run marginal cost ${ }^{16}$.

The Brown and Johnson's model has been criticized, analysed and extended in several directions by many authors ${ }^{17}$. Their solution leads a deficit and adjustment of the prices are needed under a budget constraint ${ }^{18}$. Consumers may proceed to self rationing by purchasing equipment limiting their capacity as fuses in electricity ${ }^{19}$. Among the more important extensions appear a more complicated and sophisticated exploration of the ex ante contractual possibilities like for instance the determination of priority orderings and interruptible rates. To some extent, customers are free to chose their level of probability of service i.e. their level of reliability. It should be noted that many of these authors depart from the aggregate framework considered until now and consider the preferences of the consumers as the

\footnotetext{
${ }^{16}$ Note however that under constant returns to scale, the public utility exactly breaks even.

${ }^{17}$ See among others Carlton (1977), Chao (1983) and Turvey (1970).

${ }^{18}$ See Sherman and Visscher (1978).

${ }^{19}$ See panzar and Sibley (1978).
} 
primitives. The cost function which are considered may also be more complicated that the one considered here in order to capture more realsitic situations. For instance, Chao and Wilson (1987) examine where each customer demand at most one unit of the good and has to select a rank in priority ordering to which is attached to numbers : a monetary payment and a scond one conditional upon real delively. The technology of the public utility is made up of several types of equipments (each described by its own capacity) that can activited in sequence depending upon demand but are also subject to stochastic shocks. they compare their solution to spot rpricing and stochatic rationing. These models depart significatively from the "one regulated price" model considered until now.

\section{The Model of Boiteux}

In 1951, Boiteux has published a pioneering paper which describes a market where each customer has a stochastic demand. This leads of course to an aggregate stochastic demand from the perspective of the public utility, but now there is a complete decomposition of the stochastic character of the demand across customers. He considers a model with $N$ consumers where each consumer select a consumption plan over a relevant time period, assumed to be a Gaussian random variable $\left(\mu_{i}, \sigma_{i}\right)$. The . As noted by Boiteux himself the probabilistic description of a random demand depends in general upon a large number of parameters and each of them should be subject to a specific pricing rule depending upon its implications on the total cost. He argues as followns in defense of his assumptions :" Il ne saurait être question en fait de tarifer plus de deux paramètres caractéristiques d'une même demande. L'un de ces paramètres sera la demande moyenne, caractéristique de l'importance de la consommation, l'autre un paramètre d'irrégularité choisi de manière à rendre compte des marges de sécurité nécessitées par les aléas de cette consomation. Dans le cas d'une demande collactive formée d'un grand nombre de demandes individuelles indépendantes (en probabilité), nous verrons qu'il suffit de connaitre la moyenne et l'"écart-type" de chaque demande individuelle pour calculer les dimensions à donner aux installations, marge de sécurité comprise.cette marge de sécurité est d'autant plus petite que les écarts-types des demandes individuelles sont plus plus faibles, et s'annule lorsqu'ils sont tous nuls. On est ainsi fondé dans ce cas, et de ce fait, dans la plupart des cas, à considérer l'écart type d'une demande individuelle comme le paramètre d'irrégularitê".

On the cost side, Boiteux also considers the cost function described by () and assumes $b=0$ as the treatment of the operating cost in this case does not raise any particular difficulty. He also assumes that the public utility facing this stochastic demand cost must 
meet an exogenous reliability level $\rho$ fixed by the regulator. We have already encountered this approach in the previous section; it is representative of current regulatory practices in some countries. The computation of these safety margins may be in general quite complicated. Under the assumptions considered by Boiteux, it is easy to show that the capacity which is necessary to serve the profile of demands $\left(\mu_{i}, \sigma_{i}\right)_{1 \leq i \leq N}$ under the reliability constraint attached to $\rho$ is equal to:

$$
\sum_{i=1}^{n} \mu_{i}+\Phi(\rho) \sqrt{\sum_{i=1}^{n} \sigma_{i}^{2}}
$$

where $\Phi(\rho)$ is a constant that can be read from a table of the standardized normal density function. For instance :

$$
\begin{array}{ccccc}
\rho & 0.8 & 0.9 & 0.95 & 0.99 \\
\Phi(\rho) & 0.845 & 1.285 & 1.645 & 2.325
\end{array}
$$

The total capacity cost is then :

$$
C(\boldsymbol{\mu}, \boldsymbol{\sigma})=\beta\left[\sum_{i=1}^{n} \mu_{i}+\Phi(\rho) \sqrt{\sum_{i=1}^{n} \sigma_{i}^{2}}\right]
$$

Boiteux applies the marginal cost principle to derive the price of the mean and the price of the standard deviation. In the case of customer $i$, the price of each unit of mean is equal to $\beta$ while the price of each unit of standard deviation is equal to :

$$
\frac{\sigma_{i}}{\sqrt{\sum_{i=1}^{n} \sigma_{i}^{2}}} \beta \Phi(\rho)
$$

Then, the total payment made by customer $i$ is equal to:

$$
\beta\left[\mu_{i}+\frac{\sigma_{i}^{2}}{\sqrt{\sum_{i=1}^{n} \sigma_{i}^{2}}} \Phi(\rho)\right]
$$

The Boiteux's prices call for several comments. First, we note that with these prices, the public utility breaks even ${ }^{20}$. Second, the prices are personalized : the price paid by customer $i$ for one unit of standard deviation depends upon its own standard deviation. This should not come as a surprise since the total cost function (where $\mu$ has been deleted as it does not play any role in that respect)

$$
C\left(\sigma_{1}, \sigma_{2}, \ldots, \sigma_{N}\right)=\beta \Phi(\rho)\left[\sqrt{\sum_{i=1}^{N} \sigma_{i}^{2}}\right]
$$

\footnotetext{
${ }^{20}$ The cost function is homogeneous of degree 1.
} 
is not a function of $\sqrt{\sum_{i=1}^{N} \sigma_{i}^{2}}$. This means that once uncertainty has been introduced, the commodity which was homogeneous is not homogeneous anymore. The marginal cost of customer $i$ is not the same as the marginal cost of customer $j$ whenever $\sigma_{i} \neq \sigma_{j}$. We have now a truly multiproduct firm where, using the notations of the first section, $K=N$ and $q_{k}=\sigma_{k}$ : there is a one to one correspondence between each product and each customer. These idiosyncratic marginal costs are responsible for this personalized tariffs.

Suppose now that instead of applying the marginal cost principle to derive the price of standard deviation, we use it to derive the price of variance. In such case, the price per unit of variance is equal to :

$$
\frac{1}{2 \sqrt{\sum_{i=1}^{N} \sigma_{i}^{2}}} \beta \Phi(\rho)
$$

The total payment made by customer $i$ is now equal to :

$$
\beta\left[\mu_{i}+\frac{\sigma_{i}^{2}}{2 \sqrt{\sum_{i=1}^{N} \sigma_{i}^{2}}} \Phi(\rho)\right]
$$

The part of his expenditures related to "irrégularité" has been divided by 2 and the public utility now experiments a budget deficit. Using the multiproduct analogy developed above, we note that with this change of variables i.e. $q_{k}=\sigma_{k}^{2}$ instead of $q_{k}=\sigma_{k}$ :

$$
C\left(q_{1}, q_{2}, \ldots, q_{N}\right)=\beta \Phi(\rho)\left[\sqrt{\sum_{i=1}^{N} q_{i}}\right]
$$

The function is not homogeneous of degree 1 anymore but exhibits instead decreasing returns to scale ${ }^{21}$. However, the marginal cost of each product is the same : this explains why the prices are now anonymous.

This discussion may create some confusion about what to do. can we compare the implications from the point of view of allocative efficiency of two ways of pricing demand randomness : either through the standard deviation as Boiteux did or through variance. On this matter, Drèze writes " "This situation may seem to involve an element of ambiguity; indeed it looks as if the principle of marginal cost pricing leaves room for indeterminacy when come to applications. The ambiguity might be obviated by claiming that the combination of marginal cost pricing and constant returns to scale should result in a break-even situation, so that standard deviation is the right pricing formula.... Surprisingly enough, a closer look at

\footnotetext{
${ }^{21}$ These matters bring us back to the necessity of defining carefully the commodity space, a point discussed extensively in the first part of the paper. Drèze (1964) offers a very lucid explanation along the lines exposed here and conclude after some little algebra that "uncertainty about demand will typically transform (technologically) constant returns to scale into (economically) increasing returns to scale.
} 
the problem reveals this choice to be erroneous". A careful examination of Drèze's argument shows that he rules out price discrimination as an admissible policy and derives the optimal choices of a customer $i$ as if this customer was confronted to the anonymous but nonlinear (quadratic) tariff :

$$
\left(\frac{\beta \Phi(\rho)}{\sqrt{\sum_{i=1}^{n} \sigma_{i}^{2}}}\right) \sigma_{i}^{2}
$$

We conclude that both solutions are equally acceptable from the point of view of allocative efficiency while displaying different features in terms of budget deficit and discrimination. We could certainly explore further solutions along these lines. For instance, dividing by two the above quadratic tariff restores optimality while preserving anonymity. If we want to price standard deviation under an anonymity constraint or to price variance under a budget constraint, the application of the general principles presented in the first part of the paper would lead to new set(s) of prices.

While simple, the Boiteux model is very instructive and paves the way for many useful generalizations. Boiteux himself was aware of the limitations of his own work and he suggests many interesting generalizations. We have not being very explicit about the ex post treatment of unsatisfied demands. As already discussed in the previous subsection, any welfare evaluation needs to recover some information on consumer preferences to do so. In the Boiteux model, we start from the Gaussian demands without paying attention to the behavioral responses of the customers to variations in prices. Drèze (1964) points out the necessity of this exploration. He formulates the Gaussian demand functions as fonctions of the two prices but also of the reliability level $\rho$ and writes "Questions of existence and uniqueness of the solution remain to be examined. In principle a solution may exist for any $\rho$, so $\rho$ that must be determined on independent grounds. Indeed, a reduction in $1-\rho$ may be viewed as an improvement of the quality of the product........A market solution would probably exist if the probability of shortage $1-\rho$ could be varied (together with the price attached to variance) from one individual to the next. Short of achieving such flexibility, some estimate of the consumer's surplus associated with variations $1-\rho$ of would be needed in order to choose a probability of shortage".

The first important extension proposed by Boiteux concerns what he calls the "fourniture non garantie". He writes "Nous avons passé sous silence toute une catégorie de consommateurs, ceux qui, ne demandant pas une fourniture garantie, n'exigent pas d'être servis en toutes circonstances. Clients particulièrement précieux puisque prêts à s'effacer au moment d'une pointe aléatoire de la demande, ils peuvent en revanche, participer à une meilleure 
utilisation de la marge de sécurité lorsqu'elle est partiellement inemployée. On comprend que des dispositions tarifaires particulièrement avantageuses puissent leur être offertes". He offers a very insightful analysis of the pricing issues raised by the introduction of this population of customers on order to anwer to the question : should these customers contribute to the financing of the capacity cost and, if so, what is the optimal price of this new service. He was aware of the fact that the anwer was intimely related to the intensity of the demand for this "fourniture non garantie" but admits that "son raisonnement et son résultat ne sont pas absolument rigoureux". Marchand (1974) has extended Boiteux's model in that direction. He assumes that any customer consumption plan consists of two variables : the mean as before and the maximal consumption (instead ot the variance) but instead of a single reliability level, he considers the more complicated situation where there is a finite number of such levels, ordered in sequence. This sequence describes a priority order : interruption of service can happen but has to respect that order. Any customer can suscribe ex ante for a maximum level of demand (say individual capacity) and an average demand. The allocation of the capacity follows the ordering : whenever there is some available capacity, and priorities up to the number $p$ have been served, we move to the number $p+1$. The aggregate demand at this level of priority is confronted to this residual capacity. If this capacity suffices to cover this demand, we proceed to the next priority. Otherwise, we proceed to shortage. Of course, given the announced levels of reliability, the public utility invests in a capacity to meet these conditions. Marchand determines and interpret the optimal prices.

Besides the above important and natural extension, Boiteux asserts that his results are robust to some generalizations. On one hand, the Gaussian assumption could be relaxed without changing substantially the calculation of the capacity. On the other hand, the assumption that individual demands are independent (which is quite unrealistic in many applications) can also be relaxed. However, he does not provide a detailed analysis of these extensions. These matters are examined in the next subsections.

\subsection{Kolm's Generalizations}

Kolm (1970)(1971a) provides several generalizations of the Boiteux model. Like Boiteux ${ }^{22}$, he considers the case of a finite population of $N$ customers where the demand $q^{i}$ of customer $i$ is

\footnotetext{
${ }^{22}$ Kolm (1970) presents Boiteux (1951) as a special case of his general developments but speaks very highly of him. On page 270, he writes" En 1950, Marcel Boiteux, l'un des très grands économistes français de tous les temps (et dont étant engagé dans le processus de création de science économique, nous ne pouvons nous empêcher de regretter que ses talents soient maintenant consacrés à la production d'electricité plutôt qu'à celle de théorie économique) présenta un modèle qui est un cas particulier....". We endorse this complimentary statement.
} 
a random variable described through two parameters :its mean $\mu_{i}$ and its standard deviation $\sigma_{i}$. He defends his point of view as follows "Un producteur ne sait généralement pas quelle demande de son produit se présentera à lui. Cette incertitude est coûteuse car elle empêche d'ajuster au mieux les décisions, et en particulier les équipements, à la demande qui sera effectivement servie. Une tarification de ce produit (appelé le service) doit donc présenter aux clients une note pour leur contribution à cette incertitude. Ceci pose le problème de mesurer ces incertitudes des quantités demandées. Une mesure unique de l'incertitude d'une variable incertaine est une mesure de la dispersion de ses réalisations éventuelles; elle s'annule quand cette incertitude disparaît et est positive sinon. En supposant que cet incertain est probabilisable, une mesure naturelle de cette dispersion, et de cette incertitude, est l'écarttype ou son carré, la variance. Bien sûr, les covariances entre les consommations individuelles doivent aussi en généralintervenir, car elles influencent la dispersion de la production globale, qui est leur somme. Enfin, le coût dépendra évidemment aussi des valeurs moyennes de ces grandeurs.

Cette partie et l'interprétation de la précédente pour l'incertitude diffèrent du point de vue de la tarification en ce que le tarif payé n'est plus spécifié selon l'éventualité mais dépend de l'ensemble des demandes dans toutes les éventualités par certaines fonctions de cet ensemble (ce sont des moyennes ou des dispersions) moins spécifiques en général que les demandes contingentes elles-mêmes. Pratiquement, le tarif peut être fixé selon certains types de consommation auxquels correspondent des valeurs définies de ces fonctions. en fait nous considérerons des éventualités probabilisables et ces fonctions seront des des paramètres de la distribution de probabilité des demandes. Souvent, alors, ces paramètres sont pratiquement calculés sur des séries temporelles observées des consommations en des dates en lesquelles leurs distributions jointes sont supposées identiques et indépendantes. On peut ainsi estimer les paramètres des divers types vendus de consommation. Mais souvent ce calcul a lieu pour les consommations qui sont tarifées elles-mêmes, la somme à payer étant calculée, selon une règle connue par les clients, après observation de ces quantités; sachant que ses consommations sont enregistrées et que sont calculés ces paramètres et à partir d'eux le tarif qu'il devra payer, tenant compte enfin de ses besoins, l'usager choisit le profil temporel de sa consommation".

Quite clearly, Kolm recognizes that the market and pricing environment that he considers is second-best as a "first-best" consumption plan would consist of a vector describing the demand for each contingency i.e. "éventualité" in Kolm's terminology. Subsequently, Kolm shows that there are circumstances where it is legitimate to do so. Given an ex ante decision $z$, any realization of the aggregate demand $q$ leads to a total cost equal to $C(q, z)$. If we 
consider the expected cost as the cost criterion to be considered by the public utility, then, given $z$, the ex ante total cost is equal to

$$
C(\boldsymbol{\mu}, \boldsymbol{\sigma}, z)=\int_{\Omega} C\left(\sum_{i=1}^{N} q^{i}(\omega), z\right) d \omega
$$

Optimization with respect to $z$ leads to a function $C(\boldsymbol{\mu}, \boldsymbol{\sigma})$. This function can be expressed as a function $c(\mu, \sigma)$ where $\mu$ and $\sigma$ are respectively the mean and the standard deviation of the aggregate demand if for instance $C$ is quadratic or if the aggregate demand depends upon two parameters. Then $\mu$ and $\sigma$ depends exclusively upon $\boldsymbol{\mu}$ and $\boldsymbol{\sigma}$ if the the random variables $q^{i}$ are independent or perfectly correlated. The first situation was the one considered by Boiteux. Under the above conditions, the notions of marginal cost of mean and marginal cost of standard deviation(or variance) are well defined. For instance, when :

$$
C(q, z)=C(q)=k_{0}+k_{1} q+k_{2} q^{2}
$$

where $k_{0}, k_{1}$ and $k_{2}$ are parameters with $k_{2}>0$, we obtain :

$$
\frac{\partial C}{\partial \mu}(\mu, \sigma)=k_{1}+2 k_{2} \mu, \frac{\partial C}{\partial \sigma}(\mu, \sigma)=2 k_{2} \sigma \text { and } \frac{\partial C}{\partial \sigma^{2}}(\mu, \sigma)=k_{2}
$$

When instead, we consider, almost as in Boiteux :

$$
C(q, z)=\left\{\begin{array}{c}
b q+\beta z \text { if } q \leq z \\
b q+\beta z+k(q-z) \text { if } q>z
\end{array}\right.
$$

where $k$ is positive parameter assumed to be very large, we obtain :

$$
C(\mu, \sigma, z)=b \mu+\beta z+k \int_{z}^{+\infty}(q-z) d q
$$

where $\Phi(z)$ is the probability of the event $\{\omega \in \Omega: q(\omega)>z\}$. Optimization with respect to $z$ leads to :

$$
C(\mu, \sigma)=b \mu+\beta z(\mu, \sigma)+k \int_{z(\mu, \sigma)}^{+\infty}(q-z(\mu, \sigma)) d q
$$

where $z=z(\mu, \sigma)$ is determined by the following equation :

$$
1-\Phi(z)=\frac{\beta}{k} \equiv 1-\rho
$$

We almost obtain Boiteux, as the third term does not appear in his model; the difference between this model and Boiteux is that Boiteux does not optimize with respect to $z$ and does not assume that the demand must be served ex post. Instead, the value of $z(\mu, \sigma)$ is 
deduced from an exogenous $\rho$. Kolm does not consider the above cost function but alludes to the following variant :

$$
C(q, z)=\left\{\begin{array}{c}
b q+\beta z \text { if } q \leq z \\
b q+\beta z+k \text { if } q>z
\end{array}\right.
$$

where again $k$ is positive parameter assumed to be very large. We obtain :

$$
C(\mu, \sigma, z)=b \mu+\beta z+k(1-\Phi(z))
$$

Optimization with respect to $z$ leads to :

$$
C(\mu, \sigma)=b \mu+\beta z(\mu, \sigma)+k(1-\Phi(z(\mu, \sigma)))
$$

where $z=z(\mu, \sigma)$ is determined by the following equation :

$$
\phi(z)=\frac{\beta}{k}
$$

where is the density of the aggregate random demand. In the Gaussian case we, obtain after straightforward computations :

$$
z(\mu, \sigma)=\mu+\sigma \sqrt{\log \frac{1}{2 \sigma^{2} \rho^{2} \pi}}
$$

Once the cost function $C(\mu, \sigma)$ is determined, the application of marginal cost pricing only requires the knowledge of the quantities $\frac{\partial \mu}{\partial \mu_{i}}, \frac{\partial \sigma}{\partial \sigma_{i}}$ and $\frac{\partial \sigma^{2}}{\partial \sigma_{i}^{2}}$. Of course, $\frac{\partial \mu}{\partial \mu_{i}}=1$. In the case of independence considered by Boiteux, we obtain :

$$
\frac{\partial \sigma}{\partial \sigma_{i}}=\frac{\sigma_{i}}{\sigma} \text { and } \frac{\partial \sigma^{2}}{\partial \sigma_{i}^{2}}=1
$$

In the case of perfect correlation, since :

$$
\sigma=\sum_{i=1}^{N} \sigma_{i}
$$

we obtain instead :

$$
\frac{\partial \sigma}{\partial \sigma_{i}}=1 \text { and } \frac{\partial \sigma^{2}}{\partial \sigma_{i}^{2}}=\frac{\sigma}{\sigma_{i}}
$$

Once all these informations have been collected, we derive the optimal (unit) prices for customer $i$ of mean, standard deviation and variance : 


$$
p_{\mu_{i}}=\frac{\partial C}{\partial \mu}(\mu, \sigma), p_{\sigma_{i}}=\frac{\partial C}{\partial \sigma}(\mu, \sigma) \frac{\partial \sigma}{\partial \sigma_{i}} \text { and } p_{\sigma_{i}^{2}}=\frac{\partial C}{\partial \sigma^{2}}(\mu, \sigma) \frac{\partial \sigma^{2}}{\partial \sigma_{i}^{2}}=\frac{1}{2 \sigma} \frac{\partial C}{\partial \sigma}(\mu, \sigma) \frac{\partial \sigma^{2}}{\partial \sigma_{i}^{2}}
$$

We note immediately that there is no discrimination when we price uncertainty through standard deviation in the case of independence and through variance in the case of perfect correlation. Kolm should be credited for being the first to make that important observation. Further, as cleverly observed by Kolm, the payment of any customer for uncertainty through variance pricing is equal to half the payment through standard deviation pricing. Customer $i$ pays $\frac{\sigma_{i}}{\sigma}$ less when demands are independent as opposed to correlated. We deduce that the revenues of the public utility corresponding to uncertainty when standard deviation pricing is used are twice the revenues raised when variance pricing is used. From that it is easy to deduce some results on the budget of the public utility when these pricing policies are considered. Kolm derives from these considerations general results when the cost function exhibits contant returns to scale : when standard deviation pricing is used the public utility breaks even while when variance pricing is used, only half of the total cost resulting from uncertainty is recovered. He also provides exact calculation of the budget in the quadratic case and some insights in the case where the uncertainty is moderate. In such case, he consider a Taylor development of $C(q)$ at the second order around the mean $\mu$, as an approximation of $C(q)$. He deduces :

$$
C(\mu, \sigma)=C^{\prime}(\mu)+\frac{1}{2} C^{\prime \prime}(\mu) \sigma^{2}
$$

from which the prices derived from marginal cost follow immediately.

Kolm (1971a) also contains further developments on public utility pricing when demand is stochastic. Chapter 7 examines one such environment under the heading "encombrement stochastique" while chapters 19, 20 and 21 contain a more detailed presentation and interpretation of the environment considered in Kolm (1970) and that has just been presented. I would like to conclude this section by some brief comments on these related contributions.

The environment that he calls "encombrement stochastique" is a special case of his general theory, discussed extensively in the first part of the paper, and calls for the explicit construction of the "fonction d'encombrement". The quality of the service $w$ is there measured by the reliability level but it is now assumed that the mean and dispersion parameters of the individual demands are identical and fixed and therefore beyong the scope of analysis. It is as if, once a customer gets access to the service, it is known that his behavior is random with fixed parameters of randomness. Here, the question is not to price uncertainty, but, 
instead, to price access to the service. Consider the case where $q$ is a the continuous size of the where each customer is characterized by a Gaussian demand $(\mu, \sigma)$. The aggregate demand is then a Gaussian random variable with mean $\mu q$ and standard deviation $s$ equal to $\sigma q$ in case of perfect correlation and to $\sigma \sqrt{q}$ in case of independence. The "fonction d'encombrement" is then:

$$
w(q, z)=\Phi\left(\frac{z-q \mu}{s}\right)
$$

where as before $\Phi(\rho)$ is a constant that can be read from a table of the standardized normal density function. It follows immediately that in the case of perfect correlation, the "fonction d'encombrement" exhibits constant qualitative returns. The situation is more contrasted in the case of independence. Straightforward calculations lead to :

$$
\frac{\frac{\partial w}{\partial q}(q, z)}{\frac{\partial w}{\partial z}(q, z)}=-\frac{1}{2}\left(\frac{z}{q}+\mu\right)
$$

Given the realistic presumption that $z>\mu q$, we deduce that in the case of independence, the qualitative returns are likely to be increasing. These calculations together with the general results obtained by Kolm and presented in the first half of the paper provide very sharp predictions concerning the budget of the public utility. If the marginal cost of $z$ is constant, then a public utility using optimal pricing breaks even in the case of perfect correlation and experiments a deficit equal to half of the cost of the capacity safety margin.

Boiteux-Drèze-Kolm's ideas can certainly be extended in various other directions. We have already alluded to the work of Marchand where the public utility offers different levels of liability. We could also consider the case of a public utility which is not risk neutral and derive the optimal prices of the first two moments in this new context.

\section{Implementation : Hopkinson's Tariffs and Related Matters}

While citing Boiteux, we have been very careful in making a distinction between the fluctuations considered here and the seasonal (or daily) periodic fluctuations which motivate traditionnal peak load pricing and usually takes the form of TOU (time-of-use pricing) ${ }^{23}$. The implementation of the pricing formulas discussed by Boiteux, Drèze and Kolm need as inputs the first two moments of the random demand of each customer over a given period of

\footnotetext{
${ }^{23}$ See for instance : Seeto, Woo and Horowitz (1997), Woo,Orans, Horii and Chow (1995), Woo, Chow and Horowitz (1996), and Woo, Horii and I. Horowitz (2002).
} 
time. We could consider that this period (say a month) is divided into $T$ very small intervals (say a quarter-hour) and that the real consumption of each customer is registered for each of these $T$ subperiods $^{24}$. Regarding the optimal capacity, Veall makes also the important observation that using the Gaussian distribution when the Gumbel distribution would be more appropriate leads the facility to construct insufficient capacity; this is so because it has not allowed for skewness of the peak demand. For each $i$, let us assume that the consumptions $q_{t}^{i}$ in each subperiod $t=1, \ldots, T$ are identically distributed and independent Gaussian random variables with parameters $\left(\mu_{i}, \sigma_{i}\right)$. Then, the first two empirical moments consitute good estimates of the true ones. In practice, this raises a number of questions.

First, we must be able to evaluate the quantities which are used in the calculation of these parameters and later on in the determination of the bill. As noted by Drèze (1995), "Implementation of efficient economic shemes sometimes require sophisticated technology. This can require unique ways of taking tolls in subways, metering industrial electricity, or charging for road use.Although some of these difficulties have been addressed, research and development in the area has been pursued erratically ......". Boiteux (1951) himself was pointing out that the solution could depend upon the type of commodity which is considered ; "Certains marchés comme l'électricité, se prêtent assez aisément à une différentiation très poussée de la facturation suivant le niveau d'irrégularité de chaque demande individuelle : des compteurs enregistrant le carré de la puissance appelée d'instant en instant, fournissent l'écart-type, tandis que les compteurs ordinaires indiquent la puissance moyenne. C'est là cependant un cas assez exceptionnel. La plupart des marchés ne se prêteront, en général qu'à une distinction entre quelques catégories d'abonnement, et le tarif ordinaire"

Second, instead of considering the standard deviation or the variance of consumption, we could consider the maximal 15-minute consumption i.e. the individual peak during the month. The relationship between this approach is investigated by Veall (1983) in a remarkable contribution. Consider the sequence of 15-minutes aggregate consumptions $\left(q_{1}, q_{2}, \ldots, q_{T}\right)$.Then, it can demonstrated that the limiting distribution of $q^{\max } \equiv \underset{1 \leq t \leq T}{\operatorname{Max}} q_{t}$ for large $T$ is described by the cumulative $G^{25}$ :

$$
G(q)=e^{-e^{-\left(\frac{q-l_{T}}{s_{T}}\right)}}
$$

where :

\footnotetext{
${ }^{24}$ De la Vallée Poussin (1968) adopts that framework and examines the allocation problem where, despite the existence of $T$ different Arrow-Debreu commodities, there are only two prices to decentralize the decisions of the customers. He derives and interprets the solution of this second-best market environment.

${ }^{25}$ This distribution is called the double exponential, or Gumbel distribution.
} 


$$
\begin{gathered}
l_{T}=\mu+b_{T} \sigma \text { with } b_{T} \equiv \sqrt{2 \log T}-\frac{\log (\log T)+\log 4 \pi}{2 \sqrt{2 \log T}} \\
s_{T}=a_{T} \sigma \text { with } a_{T} \equiv \frac{1}{\sqrt{2 \log T}}
\end{gathered}
$$

Given an exogenous level of reliability $\rho$, we deduce from $G(z)=\rho$ the capacity

$$
z=\mu+k \sigma \text { where } k \equiv b_{T}-a_{T} \log (-\log \rho)
$$

This capacity ${ }^{26}$ is different from the mathematical expectation of the peak:

$$
E\left(q^{\max }\right)=\mu+k^{e} \sigma \text { where } k^{e} \equiv b_{T}+\gamma a_{T}
$$

with $\gamma \simeq 0.577$ being the Euler's constant. If we take into account a possible correlation $\eta$ across individual demands, the Boiteux-Kolm prices of customer $i$ are :

$$
p_{\mu_{i}}=\beta \text { and } p_{\sigma_{i}}=\beta k \frac{\left(\sigma_{i}+\eta \sigma_{-i}\right)}{\sigma}
$$

where $\sigma_{-i} \equiv \sum_{j \neq i} \sigma_{j}$. Veal characterizes the optimal prices when $q_{i}^{\text {max }}$ is used instead of $\sigma_{i}$. Precisely, he derives the price $p_{q_{i}^{\max }}$ to be paid for the peak consumption and the price $\bar{p}_{i}$ to be paid for mean consumption :

$$
p_{q_{i}^{\max }}=\beta \frac{k}{k^{e}} \frac{\left(\sigma_{i}+\eta \sigma_{-i}\right)}{\sigma} \text { and } \bar{p}_{i}=\frac{\beta-p_{q_{i}^{\max }}}{T}
$$

Up to a change in variables, these prices are those derived from the marginal cost pricing principle by Boiteux and Kolm. The key observation is that the pair of Boiteux-Kolm prices resulting from this change of variables corresponds to a rate, the so-called Hopkinson rate, which is almost universally used by electric and gas utilities for large-volume sales to wholesales and also for their industrial clients. How can we explain that popularity ? Veall suggests that " ...the most likely answer is that it seemed to be a simple method of dividing the capacity costs according to one view of each customer's capacity requirement. The problem, of course, is that the maximum demand charge is based on individual peak demand, which may not be related to the peak system. For instance, consider a user whose peak demand is normally at 7:00 a.m. when the system peak is at 7:00 p.m. This user faces an incorrect incentive to use less electricity when there is iddle generation capacity, but has

\footnotetext{
${ }^{26}$ About the optimal capacity, Veall makes also the important observation that using the Gaussian distribution when the Gumbel distribution would be more appropriate leads the facility to construct insufficient capacity; this is so because it has not allowed for skewness of the peak demand.
} 
no special incentive to reduce usage during the peak period when capacity may be strained". Suppose, however, that coincident demand (consumption at the time of the sytem peak) and customer's peak demand are both outcomes of the same stochastic process. Then, since individual peak demand is a function of customer variance demand, the Hopkinson's rate maximum demand charge could then be a variance charge used to price each marginal user's effect on system variance and hence on optimal capacity. As noted by Veall ${ }^{27}$ " Although this argument does not provide convincing support for the Hopkinson rate as commonly applied, it may justify its use in combination with TOU rates when the demand charge is for maximum quarter-hour usage during the on-peak period".

The Hopkinson rate has been named after the pioneering work of this British engineer in 1892. He was the very first one to articulate the distinction between fixed and operating costs and to state explicitely that a customer must pay for both his share of fixed costs and for the actual consumption. Charges for fixed costs in his scheme, were assessed according to "connected load", the amount of equipment that the customer had connected. But Hopkinson's definition of maximum demand as the connected load discouraged customers from installing more lamps than aboslutely necessary, since they would be forced to pay for this load even if using it rarely. Therefore, managers turned their attention to the Wright's rate according to which maximal demand is defined as the actual maximum during the billing period and provides a special meter to measure this maximum ${ }^{28}$.

It should be noted that, in both the Boiteux-Kolm-Hopkinson and the "demand" settings, the customers are "invited" to send a signal to the public utility concerning their real or potential "needs". The flack of coincidence between the two quantities lies in the fact that uncertainty has not been resolved when the question is raised. Along these directions, quite sophisticated pricing methods have been proposed ${ }^{29}$. For the sake of illustration, we conclude this subsection byone such pricing device which has implemented by the French agency which regulates energy markets. This price is the "tarif d'utilisation des réseaux de distribution de gaz naturel" where "réseau de distribution" refers to a local transportation

\footnotetext{
${ }^{27}$ Interestingly, this remark appears already in Boiteux (1951) as he points out in concluding his paper that "..l'extension des résultats qui précèdent au cas de demandes aléatoires périodiques n'offre que des difficultés d'exposition. Les marges de sécurité n'étant nécessaires, en tant que telles, qu'au moment des pointes de la demande, ce qui vient d'être dit à propos des demandes aléatoires constantes n'est plus valable qu'au voisinage des pointes, moyennant quelques précautions".

${ }^{28}$ We refer the reader to the fascinating paper of Yakubovich, Granevotter and Mc Guire (2005) which provides an historical perspective on the development of pricing systems for electricity. The alternative to the Hopkinson-Wright's system was the Bartow's system which is a TOU rate. It is quite interesting to observe that rapidely the Wright's system was widely adopted at the expense of the Bartow's system.

${ }^{29}$ The reader will find in Energy and Environmental Economics, Inc (2006) an interesting overview of the current pricing practices in the context of electricity.
} 
network (there are several such local networks but only one global transportation network. These networks are used by large end-users which may get direct access or operators which need to use it to deliver the energy to their clients connected in that area. There is a menu of several tariffs ${ }^{30}$. Most of them are traditional two-part tariffs but one is a three-part tariff ("de type trinôme"). The last term of these three part tariff is a quantity which defines the daily capacity subscribed by the client over a year ("terme de souscription annuelle de capacité journalière". The payment is proportional to the quantity subscribed. However, things get more complicated as a client is not limited in this consumption by its subscription. Each month, the operator of the distribution network (the public utility) registers the daily differential between the real consumption and the amount which has been subscribed. A daily differential is recorded if it exceeds $5 \%$ of the subscribed capacity. The daily differential for the month is calculated as the sum of the maximal daily differential and $10 \%$ of the sum of recorded daily differentials during the month. The operator will impose a penalty on the client as soon as this number exceeds $5 \%$ of the subscribed daily capacity. this penalty is calculated as follows. For the part of the differential in between $5 \%$ and $15 \%$ of the subscribed capacity, the unit penalty per unit is equal to two times the monthly subscription ${ }^{31}$ of capacity. Finally, for the part of the differential above $15 \%$ of the subscribed capacity, the unit penalty per unit is equal to four times the monthly subscription of capacity.

\section{Advance-Purchase and Spot markets with an Appli- cation to the Regulation of Natural Gas Transporta- tion Networks}

This last subsection is devoted to the exploration of an imperfect market environment which provides a useful description of many existing (regulated or not) industries. In this setting a client will be offered two transactional opportunities : to buy some quantity on the good at time $t=0$ at some unit price $\underline{p}$ or(and) to buy some extra quantity of the good at time $t=1$ at some unit price $\bar{p}$. We will assume here that both prices are regulated which implies as in the case of a unique regulated price that ex post, clearing the market may call for some

\footnotetext{
${ }^{30}$ The tariff proposals of the French regulator (in short CRE, for Commission de Régulation de l'Energie) have been approved in December 2005 by the French government.

${ }^{31}$ Monthly subscription ("souscription mensuelle de capacité journalière") refers to the situation where the client makes reservation for a month instead of a year. The regulator has fixed different prices for these shorter periods. the rationale for these differences in prices is explored in the next subsection. In the case of our network, the price for a month reservation vary with the month and is typically higher than $\frac{1}{12}$ times the price for a year reservation. For instance in december, the factor is $\frac{4}{12}$.
} 
rationing. A customer may prefer to buy ex ante part (if not all ) of his total consumption at time 1. One one hand, the price may be smaller than the price. On the other hand, we could also imagine that the regulator offers service priority to those who made advance purchases. Hereafter, we will ignore this differentiation dimension as we will more generally ignore the risk of rationing in the behavioral response of the clients. Given a pair of prices $(\underline{p}, \bar{p})$, we will develop a structural model to derive the demand behavior in this pricing environment. Unless $\underline{p}<\bar{p}$, there is no reason for a client to proceed in advance purchases and to make reservations. When $\underline{p}<\bar{p}$, the trade-off for any client is pretty straightforward : he must balance the financial gain attached to reservation and the informational gain from delaying his decision. The consumption plan of client $i$ at $t=0$ consists of two quantities : a quantity bought in advance $\underline{q}_{i}$ we will often refer to this market as the forward market) and a quantity $\bar{q}_{i}$ bought later on the spot market when the needs will be properly estimated. From the ex ante perspective, this second quantity is a random variable. Hereafter, we will assume that the public utility forms perfect expectations about demand.

The market environment considered ${ }^{32}$ here could be augmented in several directions. If we consider for instance airline reservations, a large spectrum of options is typically offered to clients beyond the simple binary choice considered here. This specific market incompleteness and all sorts of issues raised by the assumption that the demand is stochastic have received a lot of attention in the industrial literature. For the case where the environment consists of spot markets with many suppliers facing stochastic demand but forced to precommit on a price and capacity ${ }^{33}$, several notions of competitive equilibrium have been developed where price dispersion is an equilibrium prediction : firms with high prices selling their capacity only in the event of large demand together with firms with lower prices selling their capacity in any circumstance ${ }^{34}$. The same environment has been analysed under various assumptions of imperfect competition including the limit case of a monopoly ${ }^{35}$. Finally, the consequences of permitting advance purchase discounts in such market environment have also been examined in situations of perfect and imperfect competition ${ }^{36}$.

In this subsection, we will examine this market environment from a normative perspective

\footnotetext{
${ }^{32}$ In his analysis of the institutions which might improve the situation of inefficiency resulting from the fact that trades are not contingent on the state of nature, Diamond (1980) mentions the use of a futures market.

${ }^{33}$ Precommitment to prices and capacities and demand uncertainty are central features of many industries, besides the regulated industries considered in this paper.

${ }^{34}$ The key equilibrium concept is due to Prescott (1976). For further analysis the reader may consult, for instance, Carlton (1978, 1979, 1991), Dana (1999) and Eden (1990).

${ }^{35}$ See for instance, Baron (1971), Dana (2001), Deneckere and Peck (1995) and Wilson (1988).

${ }^{36}$ See for instance, Dana (1998) and Gale and Holmes ((1992), (1993)).
} 
under the assumption that the prices on both markets are regulated. We develop a simple model to derive the behavior of consumers in such environment and then we derive the prices maximizing the aggregate net social surplus. These prices have definitively the flavor of the Boiteux-Kolm prices discussed above : the discount offered here to those proceeding to advance purchases is analogous to the premium offered in their setting to less volatile consumers. Our model is however fully specified as the preferences and informations of consumers are the basic primitives of the model. We conclude the subsection with more practical matters describing why and how these theoretical developments may be useful to analyse the policy implemented by the French regulator to regulate the access to the natural gas pipelines network.

\subsection{Demand Behavior}

In this section, we offer a simple model explaining how a client ${ }^{37}$ reacts to the pair of prices $(p, \bar{p})$ i.e. plans its gas consumption for the period $t=1$. This simple model aims not only to explain what will be the volume of gas consumed bay this client in reaction to the menu of prices but also how it will share this total consumption between an advance-purchase and the spot market. This will depends of course upon its need/preference/value for gas consumption in contrast to other commodities. The key assumption is that the valuation of this client depends upon informations which are not all disclosed at time $t=0$. Precisely, we assume that the preference of a generic household for gas consumption at time $t=1$ is described by the quasi-linear utility function ${ }^{38}$

$$
V(q, \omega)+M
$$

where $x$ denotes its consumption at $t=1, \omega$ is a real number and $M$ denotes the other consumption expenditures. We denote by $R$ the consumption budget of this household. As explained above, at time $t-=0$, this household is offered the possibility of ordering some gas at a unitary price $p$. Then at time $t=1$, he can always proceeds to some ultimate arrangements (if needed) once the all relevant information will have been conciled. It is assumed here that the real parameter $\omega$ is random and that its realization will take place at time $t$. This implies that any household planning to order some gas at time $t-=0$ faces some uncertainty. The expression in (1) describes, in monetary units, the value of the

\footnotetext{
${ }^{37}$ The model below applies in fact exclusively to households. A different model is needed to model natural gas demand by firms. The reader is refered to David, Le Breton and Merillon (2007a) for this extension.

${ }^{38}$ In order make meaningful our partial equilibrium approach.
} 
consumption plan $(q, M)$ when the realization of the random variable $\widetilde{\omega}$ is $\omega$. To evaluate ex ante, i.e. at time $t=0$, the value of this plan, we need to introduce the von NeumanMorgenstern utility $U$ of this household which reflects its attitude towards risk. The value of the consumption plan $(q, M)$ is then :

$$
U(V(q, \omega)+M)
$$

In the contractual environment considered here, a consumption plan at $\mathrm{t}=0$ is a vector $(\underline{q}, \bar{q}(\omega), M)$ where $\underline{x}$ represents its advance purchase at time $t-\Delta$ and $\bar{q}(\omega)$ represents its spot purchase at time $t=1$ when uncertainty has been resolved : $\bar{q}(\omega)$ denotes its purchase when the realization of the random variable is $\omega$. When the range of the random variable $\widetilde{\omega}$ consists of a finite set $\Omega$ and $\pi(\omega)$ is the probability of the event $\{\widetilde{\omega}=\omega\}$, the expected utility derived from the purchase plan $(\underline{q}, \bar{q}(\omega), M)$ is :

$$
\sum_{\omega \in \Omega} \pi(\omega) U(V(\underline{q}+\bar{q}(\omega), \omega)-\underline{p q}-\overline{p q}(\omega)+R)
$$

The first order conditions are :

$$
\sum_{\omega \in \Omega} \pi(\omega) U^{\prime}(V(\underline{q}+\bar{q}(\omega), \omega)-\underline{q} \underline{x}-\overline{p q}(\omega)+R)\left[\frac{\partial V}{\partial x}(\underline{q}+\bar{q}(\omega), \omega)-\underline{p}\right]=0 \text { si } \underline{q}>0
$$

and

$$
\frac{\partial V}{\partial x}(\underline{q}+\bar{q}(\omega), \omega)-\bar{p}=0 \text { si } \bar{q}(\omega)>0
$$

Without any further assumption on the primitives, equations (3)and (4) are not easy to solve in full generality. For instance, when $U$ is of the CARA type i.e. $U(z)=-e^{-\lambda z}$ where $\lambda$ is a positive parameter, equation (3) simplifies to :

$$
\left.\sum_{\omega \in \Omega} \pi(\omega) e^{-\lambda(V(\underline{q}+\bar{q}(\omega), \omega)-\overline{p q}(\omega)}\right)\left[\frac{\partial V}{\partial x}(\underline{q}+\bar{q}(\omega), \omega)-\underline{p}\right]=0
$$

Note however that $U$ does not play any role in equations (4) which is fairly natural as they describe optimal supplementary purchase of gas once uncertainty has totally disappeared. Hereafter, we limit our attention to the case where clients are risk neutral. In this case, equation (3) simplifies to :

$$
\sum_{\omega \in \Omega} \pi(\omega)\left[\frac{\partial V}{\partial x}(\underline{x}+\bar{x}(\omega), \omega)-\underline{p}\right]=0 \text { if } \underline{x}>0
$$




\subsection{Aggregate Demand under Further Specifications}

We now consider a population of $N$ clients where the behavior of each client $i=1, \ldots, N$ is described as in the above subsection ${ }^{39}$. We introduce some further specifications on the primitives in order to derive a simpler description of the aggregate behavior. This is mostly done by describing the influence of uncertainty on the value of gas consumption. The key assumption is the binomial character of the stochastic influence of the state of the world $\omega$ : for each client $i$ either the state of the world is favorable to gas consumption $x_{i}$ or it is not. Moreover, the states of the world favorable to gas consumption may differ sharply accross clients. A state of the world is a vector describing the population of clients receiving a favorable signal. Precisely :

$$
\Omega=\prod_{i=1}^{I^{1}}\left\{\underline{\omega}_{i}, \bar{\omega}_{i}\right\}
$$

where for all $i=1,2, \ldots, N, \underline{\omega}_{i}$ et $\bar{\omega}_{i}$ are two real numbers such that : $\underline{\omega}_{i}<\bar{\omega}_{i}$. Without loss of generality, we suppose hereafter that $\underline{\omega}_{i}=0 ; \bar{\omega}_{i}$ refers to circumstances unfavorable to gas consumption from the perspective of client $i$. We denote $\pi_{i}$ the probability of the event $\left\{\omega_{i}(t)=0\right\}$.

Finally, we assume that for all $i=1, \ldots, N$ :

$$
V_{i}\left(q_{i}, \omega\right)=v_{i}\left(q_{i}+\omega_{i}\right)
$$

where $v_{i}$ is an increasing and strictly concave continuously differentiable function. In this simplified setting, a consumption purchase plan is a three dimensional vector $\left(\underline{q}_{i}\right.$, $\left.\bar{q}_{i}\left(\underline{\omega}_{i}\right), \bar{q}_{i}\left(\bar{\omega}_{i}\right)\right)=\left(\underline{q}_{i}, \bar{q}_{i}(0), \bar{q}_{i}\left(\bar{\omega}_{i}\right)\right)$. The expected utility of client $i$ for such plan becomes :

$$
\pi_{i} v_{i}\left(\underline{q}_{i}+\bar{q}_{i}\left(\underline{\omega}_{i}\right)\right)+\left(1-\pi_{i}\right) v_{i}\left(\underline{q}_{i}+\bar{q}_{i}\left(\bar{\omega}_{i}\right)+\bar{\omega}_{i}\right)-\underline{p q}_{i}-\bar{p}\left(\pi_{i} \bar{q}_{i}(0)+\left(1-\pi_{i}\right) \bar{q}_{i}\left(\bar{\omega}_{i}\right)\right)
$$

Equations (4) simplifies to :

$$
\left\{\begin{array}{c}
v_{i}^{\prime}\left(\underline{q}_{i}+\bar{q}_{i}(0)\right)=\bar{p} \text { iff } v_{i}^{\prime}\left(\underline{q}_{i}\right) \geq \bar{p} \\
v_{i}^{\prime}\left(\underline{q}_{i}+\bar{x}_{i}\left(\bar{\omega}_{i}\right)+\bar{\omega}_{i}\right)=\bar{p} \text { iff } v_{i}^{\prime}\left(\underline{q}_{i}+\bar{\omega}_{i}\right) \geq \bar{p}
\end{array}\right.
$$

If $v_{i}^{\prime}\left(\underline{q}_{i}\right)<\bar{p}$ (respectively $\left.v_{i}^{\prime}\left(\underline{q}_{i}+\bar{\omega}_{i}\right)<\bar{p}\right)$, then $\bar{q}_{i}(0)=0$ (respectively $\bar{q}_{i}\left(\bar{\omega}_{i}\right)=0$ ). Since $v_{i}$ has been assumed to be strictly concave, we deduce that if $v_{i}^{\prime}\left(\underline{q}_{i}\right)<\bar{p}$ then $v_{i}^{\prime}\left(\underline{q}_{i}-\bar{\omega}_{i}\right)<\bar{p}$.

\footnotetext{
${ }^{39}$ The parameters and variables will be subsequently indexed with $i: V_{i}, \Omega_{i}, \pi_{i}$ and $R_{i}$. Heterogeneity across households can be (at this stage) multidimensional. Under quasi linearity, income ffects are eliminated. We are left with two channels : the impact of $q$ for a given $\omega$ and the impact of $\omega$ for a given $q$.
} 
Therefore, from (6), if $\bar{q}_{i}\left(\bar{\omega}_{i}\right)>0$, then $\bar{q}_{i}(0)>0$. On the other hand, equation (18) simplifies to :

$$
\pi_{i} v_{i}^{\prime}\left(\underline{q}_{i}+\bar{q}_{i}(0)\right)+\left(1-\pi_{i}\right) v_{i}^{\prime}\left(\underline{q}_{i}+\bar{q}_{i}\left(\bar{\omega}_{i}\right)+\bar{\omega}_{i}\right)=\underline{p} \text { si } \underline{q}_{i}>0
$$

We deduce from equations (6) et (7) that necessarily :

$$
\bar{q}_{i}\left(\bar{\omega}_{i}\right)=0
$$

Indeed, if on the contrary $\bar{q}_{i}\left(\bar{\omega}_{i}\right)>0$, since $\bar{q}_{i}(0)>0$, we deduce from $(6)$ :

$$
\pi_{i} v_{i}^{\prime}\left(\underline{q}_{i}+\bar{q}_{i}(0)\right)+\left(1-\pi_{i}\right) v_{i}^{\prime}\left(\underline{q}_{i}+\bar{q}_{i}\left(\bar{\omega}_{i}\right)+\bar{\omega}_{i}\right)=\bar{p}
$$

which contradicts $(7)$ since $\bar{p}>\underline{p}$. The intuition driving this result is fairly simple. Here, a circumstance which is adverse to gas consumption leads to a decrease of the marginal utility of gas with respect to a reference consumption. In our binary setting, this happens when $\omega_{i}=\bar{\omega}_{i}$ and in such case, it is optimal to purchase the contingent optimal quantity of gas at the lowest possible price i.e. in advance. If in contrast, circumstances turn to be favorable, then the spot market will be (likely) used to proceed to some additional purchases. An immediate implication of this observation is that a purchase plan of client $i$ reduces to a two dimensional vector $\left(\underline{q}_{i}, \bar{q}_{i}(0)\right)$, that we will denote simply $\left(\underline{q}_{i}, \bar{q}_{i}\right)$. The first order conditions become :

$$
\pi_{i} v_{i}^{\prime}\left(\underline{q}_{i}+\bar{q}_{i}\right)+\left(1-\pi_{i}\right) v_{i}^{\prime}\left(\underline{q}_{i}+\bar{\omega}_{i}\right)=\underline{p} \text { if } \underline{q}_{i}>0
$$

and

$$
v_{i}^{\prime}\left(\underline{q}_{i}+\bar{q}_{i}\right)=\bar{p} \text { si } \bar{q}_{i}>0
$$

Client $i$ finds optimal to purchase its gas in advance if the unique solution $\underline{q}_{i}$ of the following equation :

$$
\pi_{i} v_{i}^{\prime}\left(\underline{q}_{i}\right)+\left(1-\pi_{i}\right) v_{i}^{\prime}\left(\underline{q}_{i}+\bar{\omega}_{i}\right)=\underline{p}
$$

satisfies 


$$
v_{i}^{\prime}\left(\underline{q}_{i}\right) \leq \bar{p}
$$

Similarly, client $i$ finds optimal to purchase all its gas on the spot market if :

$$
\pi_{i} v_{i}^{\prime}\left(\bar{q}_{i}\right)+\left(1-\pi_{i}\right) v_{i}^{\prime}\left(\bar{\omega}_{i}\right) \leq \underline{p}
$$

where $\bar{q}_{i}$ is the unique solution of the equation:

$$
v_{i}^{\prime}\left(\bar{q}_{i}\right)=\bar{p}
$$

This happens if and only if the following inequality holds true:

$$
v_{i}^{\prime}\left(\bar{\omega}_{i}\right) \leq \frac{\underline{p}-\pi_{i} \bar{p}}{1-\pi_{i}}
$$

For instance when $\underline{p}$ is smaller than $\pi_{i} \bar{p}$, we conclude that this cannot happen. The inequality is less likely to hold true when $\underline{p}$ is small, $\bar{p}$ is large and $v_{i}^{\prime}\left(\bar{\omega}_{i}\right)$ is large. In contrast, the effect of $\pi_{i}$ is ambiguous.

Finally, client i will not purchase gas (at all) if :

$$
\pi_{i} v_{i}^{\prime}(0)+\left(1-\pi_{i}\right) v_{i}^{\prime}\left(\bar{\omega}_{i}\right) \leq \underline{p} \text { et } v_{i}^{\prime}(0) \leq \bar{p}
$$

Let $\underline{q}_{i}(\underline{p})$ be the unique solution to equation (9). Inequality (10) becomes :

$$
\bar{p} \geq \frac{\underline{p}-\left(1-\pi_{i}\right) v_{i}^{\prime}\left(\underline{q}_{i}(\underline{p})+\bar{\omega}_{i}\right)}{\pi_{i}} \equiv \varphi_{i}(\underline{p})
$$

From the implicit function theorem, we deduce :

$$
\underline{x}_{i}^{\prime}(\underline{p})=\frac{1}{\pi_{i} v_{i}^{\prime \prime}\left(\underline{q}_{i}\right)+\left(1-\pi_{i}\right) v_{i}^{\prime \prime}\left(\underline{q}_{i}+\bar{\omega}_{i}\right)}
$$

and then :

$$
\varphi_{i}^{\prime}(\underline{p})=\frac{1-\frac{\left(1-\pi_{i}\right) v_{i}^{\prime \prime}\left(q_{i}+\bar{\omega}_{i}\right)}{\pi_{i} v_{i}^{\prime \prime}\left(\underline{q}_{i}\right)+\left(1-\pi_{i}\right) v_{i}^{\prime \prime \prime}\left(\underline{q}_{i}+\bar{\omega}_{i}\right)}}{\pi_{i}}=\frac{v_{i}^{\prime \prime}\left(\underline{q}_{i}\right)}{\pi_{i} v_{i}^{\prime \prime}\left(\underline{q}_{i}\right)+\left(1-\pi_{i}\right) v_{i}^{\prime \prime}\left(\underline{q}_{i}+\bar{\omega}_{i}\right)}
$$

It should be noted that as soon as $v_{i}^{\prime}(x)$ tends to 0 when $x$ tends to $+\infty, \varphi_{i}(\underline{p})$ tends to 0 when $\underline{p}$ tends to 0 . Moreover, combining (11) and (12) leads to the inequality : 


$$
\bar{p} \leq \frac{\underline{p}-\left(1-\pi_{i}\right) v_{i}^{\prime}\left(\bar{\omega}_{i}\right)}{\pi_{i}} \equiv \psi_{i}(\underline{p})
$$

The functions $\varphi_{i}$ et $\psi_{i}$ make the identification of the four potential groups of households in the population easier : those who do consume gas, those who purchase their gas exclusively in advance, those who purchase their gas exclusively on the spot market and those who mix with the both. It is useful to note that the functions intersect at $\underline{p}=\pi_{i} v_{i}^{\prime}(0)+\left(1-\pi_{i}\right) v_{i}^{\prime}\left(\bar{\omega}_{i}\right)$ and $\varphi_{i}(\underline{p})=\psi_{i}(\underline{p})=v_{i}^{\prime}(0)$. The curvature of the function $\varphi_{i}$ depends upon the monotonicity of the coefficient $-\frac{v_{i}^{\prime \prime}(x)}{v_{i}^{\prime \prime}(x)}$. The derivation of the functions $\varphi_{i}$ and $\psi_{i}$ is straighforward. For instance, when $v_{i}(x)=-e^{-\lambda_{i} x}$ where $\lambda_{i}$ is a positive parameter, we obtain :

$$
\varphi_{i}(\underline{p})=\frac{\underline{p}}{\pi_{i}+\left(1-\pi_{i}\right) e^{-\lambda_{i} x}} \text { and } \psi_{i}(\underline{p})=\frac{\underline{p}-\left(1-\pi_{i}\right) \lambda_{i} e^{-\lambda_{i} x}}{\pi_{i}}
$$

At time $t=1$, the total gas consumption of household $i$ is the realization of a Bernouilli random variable with mean $\underline{q}_{i}(\underline{p}, \bar{p})+\pi_{i} \bar{q}_{i}(\underline{p}, \bar{p})$ and standard deviation $\sqrt{\pi_{i}\left(1-\pi_{i}\right)} \bar{q}_{i}(\underline{p}, \bar{p})$. If the client is "interior" i.e. if he purchases natural gas on both markets, then the determination of his demands uses simply the inverse function of $v_{i}^{\prime}$ denoted hereafter by $\Psi_{i}$.

To obtain a complete description of the aggregate demand behavior, it remains to describe the structure of the uncertainty. We have assumed that each client $i$ is described by a Bernouilli model totally summarized by a single number $\pi_{i}$ representing the marginal distribution attached to this client. The aggregate behavior will depend upon the joint distribution accross clients. For instance, in the case of two clients i.e. when $N=2$, a state of the world is described by a vector $\omega \in\left\{0, \bar{\omega}_{1}\right\} \times\left\{0, \bar{\omega}_{2}\right\}$. the joint distribution is defined by the following contingency table ${ }^{40}$ :

\begin{tabular}{|l||l|l||l|}
\hline & 0 & $\bar{\omega}_{2}$ & \\
\hline \hline 0 & $\rho \pi_{1} \pi_{2}$ & $\pi_{1}\left(1-\rho \pi_{2}\right)$ & $\pi_{1}$ \\
\hline $\bar{\omega}_{1}$ & $\pi_{2}\left(1-\rho \pi_{1}\right)$ & $1-\pi_{1}-\pi_{2}+\rho \pi_{1} \pi_{2}$ & $1-\pi_{1}$ \\
\hline \hline & $\pi_{2}$ & $1-\pi_{2}$ & \\
\hline
\end{tabular}

The last row and last colum correspond to the marginals. All the information about the correlation accross states is contained in the coefficient $\rho$. The circumstances influencing the

\footnotetext{
${ }^{40}$ An alternative way to model simply the correlation would consist in adding an extra component in the product space $\prod_{i=1}^{N}\left\{\underline{\omega}_{i}, \bar{\omega}_{i}\right\}$, say $\Omega=\{\underline{\theta}, \bar{\theta}\} \times \prod_{i=1}^{N}\left\{\underline{\omega}_{i}, \bar{\omega}_{i}\right\}$ and assuming the joint distribution as the product of the marginals. In such setting, the uncertainty affecting client $i$ would consist of two terms : a macroeconomic or climatic term $\theta$ together with an idiosyncratic term $\omega_{i}$. The analysis of the demand of gas by households and firms could be conducted as before, under the asssumption that $V_{i}\left(q_{i}, \omega\right)=v_{i}\left(q_{i}+\theta+\omega_{i}\right)$. However, there are four distinct states of the world for each client and the analytics become more tedious.
} 
gas demand of the two clients are independent when $\rho=1$. This is the Boiteux's case. In contrast, they are perfectly correlated when $\rho=\frac{1}{\pi_{1}}=\frac{1}{\pi_{2}}$. This is the Kolm's case.

Hereafter, we limit our attention to the case of independence i.e. only the idiosyncratic risk is taken into consideration. From the perspective of the public utility serving this population of clients, the stochastic demand of gas for consumption at time $t=1$ is therefore a sum of independent (but not identically distributed) Bernouilli random variables $\widetilde{q}_{i}$ where

$$
\widetilde{q}_{i}=\left\{\begin{array}{l}
\underline{q}_{i}(\underline{p}, \bar{p})+\bar{q}_{i}(\underline{p}, \bar{p}) \text { with probability } \pi_{i} \\
\underline{q}_{i}(\underline{p}, \bar{p}) \text { with probability } 1-\pi_{i}
\end{array}\right.
$$

The aggregate demand consists of a deterministic term $\sum_{i=1}^{N} \underline{q}_{i}(\underline{p}, \bar{p})$ and a random term $\sum_{i=1}^{N} \bar{q}_{i}(\underline{p}, \bar{p})$. The first term is the aggregate advance purchase while the second terme is the aggregate purchase on the spot market. Both are influenced by the two dimensional price policy $(\underline{p}, \bar{p})$.

Hereafter, under the assumption that $N$ is a large number, we will replace the exact aggregate demand by its Gaussian approximation. If for some $\delta>0$ :

$$
\frac{\sum_{i=1}^{N} \pi_{i}\left(1-\pi_{i}\right)\left(\pi_{i}^{1+\delta}+\left(1-\pi_{i}\right)^{1+\delta}\right)\left(\bar{q}_{i}\left(\bar{\omega}_{i}\right)\right)^{2+\delta}}{\left(\sqrt{\sum_{i=1}^{N} \sigma_{i}^{2}}\right)^{2+\delta}} \underset{N \rightarrow \infty}{\rightarrow} 0
$$

we deduce from the Lyapounov 's central limit theorem that if $N$ is large enough, $q(\underline{p}, \bar{p}) \equiv \sum_{i=1}^{N}\left(\underline{x}_{i}(\underline{p}, \bar{p})+\bar{x}_{i}(\underline{p}, \bar{p})\right)$ behaves approximatively as a Gaussian random variable $N(\mu, \sigma)$ where

$$
\begin{gathered}
\mu=\sum_{i=1}^{N} \mu_{i} \text { with } \mu_{i}=\underline{q}_{i}(\underline{p}, \bar{p})+\pi_{i} \bar{q}_{i}(\underline{p}, \bar{p}) \text { for all } i=1, \ldots, N \\
\sigma=\sqrt{\sum_{i=1}^{N} \sigma_{i}^{2} \text { with } \sigma_{i}=\sqrt{\pi_{i}\left(1-\pi_{i}\right)} \bar{q}_{i}(\underline{p}, \bar{p}) \text { for all } i=1, \ldots, N}
\end{gathered}
$$

\subsection{Optimal Public Utility Pricing}

We are now in position to derive the optimal "Gaussian" prices. By optimal, we mean here prices that maximize the social objective defined as the sum of the aggregate net surplus of clients and the benefit(or loss) of the firm. We will not pay attention here to the issue of budget deficit and the cost of public funds ${ }^{41}$. On the cost side, we will proceed as in Boiteux

\footnotetext{
${ }^{41}$ The calculation of Ramsey-Boiteux's prices in this context can be obtained from the authors upon request.
} 
i.e. we assume that there is an exogenous level of reliability $\rho$ and that the capacity $z$ determined to meet this quality of service. As already shown, while presenting the Boiteux's model, the total capacity cost is as follows:

$$
\begin{aligned}
& \beta\left[\sum_{i=1}^{I^{1}}\left(\underline{x}_{i}(\underline{p}, \bar{p})+\pi_{i} \bar{x}_{i}(\underline{p}, \bar{p})\right)+\sum_{j=1}^{I^{2}}\left(\underline{x}_{j}(\underline{p}, \bar{p})+\pi_{j} \bar{x}_{j}(\underline{p}, \bar{p})\right)\right. \\
& +\Phi(\rho) \sqrt{\left.\sum_{i=1}^{I^{1}} \pi_{i}\left(1-\pi_{i}\right) \bar{x}_{i}^{2}(\underline{p}, \bar{p})+\sum_{j=1}^{I^{2}} \pi_{j}\left(1-\pi_{j}\right) \bar{x}_{j}^{2}(\underline{p}, \bar{p})\right]} .
\end{aligned}
$$

The optimization problem is then formulated as follows :

$$
\begin{aligned}
& \max _{\underline{p}, \bar{p}}\left[\sum_{i=1}^{N} \pi_{i} v_{i}\left(\underline{q}_{i}(\underline{p}, \bar{p})+\bar{q}_{i}(\underline{p}, \bar{p})\right)+\left(1-\pi_{i}\right) v_{i}\left(\underline{q}_{i}(\underline{p}, \bar{p})+\bar{\omega}_{i}\right)\right] \\
& -\beta\left[\sum_{i=1}^{N}\left(\underline{q}_{i}(\underline{p}, \bar{p})+\pi_{i} \bar{q}_{i}(\underline{p}, \bar{p})\right)\right]-\beta \Phi(\rho)\left[\sqrt{\sum_{i=1}^{N} \pi_{i}\left(1-\pi_{i}\right) \bar{q}_{i}^{2}(\underline{p}, \bar{p})}\right] .
\end{aligned}
$$

Under the symmetry assumption $\pi_{i}=\pi$ for all $i=1, \ldots N$, it can be demonstrated ${ }^{42}$ that the optimal pricing policy $\left(\underline{p}^{*}, \bar{p}^{*}\right)$ is solution of the following pair of equations :

$$
\underline{p}^{*}-\beta=(1-\pi)\left(\bar{p}^{*}-\beta\right)-\beta \Phi(\rho) \sqrt{\pi(1-\pi)} \frac{A(\underline{p}, \bar{p})}{B(\underline{p}, \bar{p}) \sqrt{\sum_{i=1}^{N}\left(\bar{q}_{i}\left(\bar{\omega}_{i}\right)(\underline{p}, \bar{p})\right)^{2}}}
$$

and

$$
\bar{p}^{*}=\beta+\frac{\pi \beta \Phi(\rho)}{\sqrt{\pi(1-\pi)}} \frac{C\left(\underline{p}^{*}, \bar{p}^{*}\right)}{D\left(\underline{p}^{*}, \bar{p}^{*}\right) \sqrt{\sum_{i=1}^{N}\left(\bar{q}_{i}\left(\bar{\omega}_{i}\right)\left(\underline{p}^{*}, \bar{p}^{*}\right)\right)^{2}}}
$$

where :

$$
\begin{gathered}
A(\underline{p}, \bar{p}) \equiv \sum_{i=1}^{N} \Psi_{i}^{\prime}\left(\frac{\underline{p}-(1-\pi) \bar{p}}{\pi}\right) \bar{q}_{i}\left(\bar{\omega}_{i}\right)(\underline{p}, \bar{p}) \\
B(\underline{p}, \bar{p}) \equiv \sum_{i=1}^{N} \Psi_{i}^{\prime}\left(\frac{\underline{p}-(1-\pi) \bar{p}}{\pi}\right)
\end{gathered}
$$

\footnotetext{
${ }^{42}$ The details of the proof are available from the authors upon request.
} 


$$
C(\underline{p}, \bar{p}) \equiv \sum_{i=1}^{N} \Psi_{i}^{\prime}(\bar{p}) \bar{q}_{i}\left(\bar{\omega}_{i}\right)(\underline{p}, \bar{p})
$$

and

$$
D(\underline{p}, \bar{p}) \equiv \sum_{i=1}^{N} \Psi_{i}^{\prime}(\bar{p})
$$

These price equations are complicated and not easy to interpret in this general framework where no limits on the heterogeneity across consumers have been imposed

In the fully symmetric case, i.e. under the extra assumption

$$
\Psi_{i}^{\prime}(p)=\Psi_{j}^{\prime}(p) \text { and } \bar{\omega}_{i}=\bar{\omega}_{j} \text { for all } i, j=1, \ldots N \text { and all } p>0
$$

we obtain the following simple formulas for the optimal prices :

$$
\bar{p}^{*}=\beta+\frac{\sqrt{\pi} \beta \Phi(\rho)}{\sqrt{N} \sqrt{(1-\pi)}}
$$

and

$$
\underline{p}^{*}=\beta
$$

Formula (16) is transparent : the capacity component of the price of gas on the forward market is exactly equal to the marginal cost of capacity. Formula (15) asserts therefore that the price differential satisfies :

$$
\frac{\bar{p}^{*}}{\underline{p}^{*}}=1+\frac{\Phi(\rho)}{\sqrt{N}} \sqrt{\frac{\pi}{1-\pi}}
$$

The second term reflects the premium offered to a consumer who buy his gas ${ }^{43}$ on the forward market : the magnitude of this premium declines with the the population size, which is not surprising, since in the independence case considered here, the uncertainty tends to collapse when the population becomes large. Otherwise the premium increases with the safety margin and the probability $\pi$.

\footnotetext{
${ }^{43} \mathrm{We}$ could also interpret this premium in the context of the pricing of transport services ( like airlines or railways) as the discount offered to a customer buying his ticket long in advance in constrast to a customer buying his ticket in the last moment.
} 
These second best prices inherate some of the features of the marginal cost pricing. In fact, they are not so distant from the Boiteux-Kolm prices. To some extent, $\underline{p}^{*}$ stands for the price of average consumption while $\bar{p}^{*}-\underline{p}^{*}$ would represent the price of dispersion. The general formulas have been derived under a weak symmetry assumption in order to eliminate the ex ante differences across clients other than their tastes. The fact that the pricing formulas does not exhibit simplicity, despite this step in direction of more population homogeneity, is due to the existence of idiosyncratic impacts on the cost. Since by assumption, the price $\bar{p}$ is uniform, it cannot accomodate the differences in costs, resulting from these differences ${ }^{44}$. Except for this aggregation operation, the capacity component of the price of gas on the spot market is higher that the corresponding price on the forward market by an amount

$$
\frac{\beta \Phi(\rho)}{D\left(\underline{p}^{*}, \bar{p}^{*}\right) \sqrt{\sum_{i=1}^{N}\left(\bar{q}_{i}\left(\bar{\omega}_{i}\right)\left(\underline{p}^{*}, \bar{p}^{*}\right)\right)^{2}}}\left[\frac{\sqrt{\pi(1-\pi)} A\left(\underline{p}^{*}, \bar{p}^{*}\right)}{B\left(\underline{p}^{*}, \bar{p}^{*}\right)}+\frac{\pi^{2} C\left(\underline{p}^{*}, \bar{p}^{*}\right)}{D\left(\underline{p}^{*}, \bar{p}^{*}\right) \sqrt{\pi(1-\pi)}}\right]
$$

To get a better understanding of the parameters which will have an influence on the determination of these prices, consider the following simple asymmetric setting. The population is composed of two classes of clients : there are $N^{l}(l=1,2)$ identical clients in each group i.e.

$$
\begin{aligned}
\pi_{i} & \equiv \pi^{1}, v_{1} \equiv v^{1}, \bar{\omega}_{i} \equiv \bar{\omega}^{1} \text { pour } i=1, \ldots, N^{1} . \\
\pi_{j} & \equiv \pi^{2}, v_{j} \equiv v^{2}, \bar{\omega}_{j} \equiv \bar{\omega}^{2} \text { pour } j=1, \ldots ., N^{2} .
\end{aligned}
$$

If the solution is interior, the first order conditions lead to the equations :

$$
\begin{aligned}
& (\underline{p}-\beta)\left[\gamma e^{1}+e^{2}\right]-(\bar{p}-\beta)\left[\gamma \pi^{1} e^{1}+\pi^{2} e^{2}\right] \\
= & -\beta \Phi(\rho)\left[\frac{\gamma^{2} \pi^{1} I^{2}\left(1-\pi^{1}\right) \beta_{1} e^{1}+\pi^{2} \beta_{2} I^{1}\left(1-\pi^{2}\right) e^{2}}{\sqrt{I^{1}\left(I^{2}\right)^{2} \pi^{1}\left(1-\pi^{1}\right)\left(\beta_{1}\right)^{2} \gamma^{2}+I^{2}\left(I^{2}\right)^{2} \pi^{2}\left(\beta_{2}\right)^{2}\left(1-\pi^{2}\right)}}\right] \\
= & -\theta \Phi(\alpha)\left[\frac{\frac{\gamma^{2} \pi^{1}\left(1-\pi^{1}\right) \beta_{1} e^{1}}{I^{1}}+\frac{\pi^{2} \beta_{2}\left(1-\pi^{2}\right) e^{2}}{I^{2}}}{\sqrt{\frac{\pi^{1}\left(1-\pi^{1}\right)\left(\beta_{1}\right)^{2} \gamma^{2}}{I^{1}}+\frac{\pi^{2}\left(\beta_{2}\right)^{2}\left(1-\pi^{2}\right)}{I^{2}}}}\right],
\end{aligned}
$$

\footnotetext{
${ }^{44}$ This uniformity or non discrimination constraint is a second best-best constraint that has been analysed by several authors including Kolm. The optimal price results from the minimization of a weighted average of the distorsions.
} 
et

$$
\begin{aligned}
& (\underline{p}-\theta)\left[\gamma f^{1}+f^{2}\right]+(\bar{p}-\theta)\left[\gamma \pi^{1} \alpha_{1} g^{1}+\pi^{2} \alpha_{2} g^{2}\right] \\
= & \beta \Phi(\rho)\left[\frac{\gamma N^{2} \pi^{1}\left(1-\pi^{1}\right)\left(\alpha_{1}\right)^{2} g^{1}+\pi^{2} N^{1}\left(1-\pi^{2}\right)\left(\alpha_{2}\right)^{2} g^{2}}{\sqrt{N^{1}\left(N^{2}\right)^{2} \pi^{1}\left(1-\pi^{1}\right)\left(\alpha_{1}\right)^{2} \gamma^{2}+N^{2}\left(N^{2}\right)^{2} \pi^{2}\left(\alpha_{2}\right)^{2}\left(1-\pi^{2}\right)}}\right] \\
= & \beta \Phi(\rho)\left[\frac{\frac{\gamma^{2} \pi^{1}\left(1-\pi^{1}\right)\left(\alpha_{1}\right)^{2} g^{1}}{N^{1}}+\frac{\pi^{2}\left(\alpha_{2}\right)^{2}\left(1-\pi^{2}\right) g^{2}}{N^{2}}}{\sqrt{\frac{\pi^{1}\left(1-\pi^{1}\right)\left(\alpha_{1}\right)^{2} \gamma^{2}}{N^{1}}+\frac{\pi^{2}\left(\alpha_{2}\right)^{2}\left(1-\pi^{2}\right)}{N^{2}}}}\right],
\end{aligned}
$$

where for $i=1,2$

$$
\begin{aligned}
\gamma & \equiv \frac{I^{1} \underline{q}^{1}(\underline{p}, \bar{p})}{I^{2} \underline{q}^{2}(\underline{p}, \bar{p})}, \alpha_{i} \equiv \frac{\bar{q}^{i}(\underline{p}, \bar{p})}{\underline{q}^{i}(\underline{p}, \bar{p})}, e^{i} \equiv \frac{\partial \underline{d}^{i}(\underline{p}, \bar{p})}{\partial \underline{p}} \frac{\underline{p}}{\underline{q}^{i}(\underline{p}, \bar{p})} \\
f^{i} & \equiv \frac{\partial \underline{q}^{i}(\underline{p}, \bar{p})}{\partial \bar{p}} \frac{\bar{p}}{\underline{q}^{i}(\underline{p}, \bar{p})} \partial \bar{p} \text { et } g^{i} \equiv \frac{\partial \bar{q}^{i}(\underline{p}, \bar{p})}{\partial \bar{p}} \frac{\bar{p}}{\bar{q}^{i}(\underline{p}, \bar{p})} \partial \bar{p}
\end{aligned}
$$

David, Le Breton and Merillon (2007) refer to these equations as the fundamental price equations as they provide the optimal second-best distorsions between the prices and the marginal capacity cost and highlight the relevant parameters.

- The parameter $\gamma \equiv N^{1} \underline{q}^{1}(\underline{p}, \bar{p}) / N^{2} \underline{q}^{2}(\underline{p}, \bar{p})$ measuring the market shares of the two groups.

- The parameters $\alpha^{1}$ and $\alpha^{2}$ measuring the ratio of the volumes of transactions on the two markets.

- The different cross and direct price elasticities: $e^{1}, e^{2}, f^{1}, f^{2}, g^{1}$ et $g^{2}$;

- The volatility of the two groups evaluated through the parameters $\pi^{1}$ et $\pi^{2}$.

It is important to observe that the parameters which appear in these equations are not all logically independent as they are related through the first order conditions of the clients. For instance, we always have :

$$
f^{i}=-\pi^{i} e^{i} \text { for } i=1,2
$$

It is also important to remark that these equations does not provide a closed form analytic solution as (like in Ramsey-Boiteux's equations) the parameters may depend upon the prices $\underline{p}$ and $\bar{p}$. These non linear equations may be quite complicated.

If $\pi^{1}=\pi^{2} \equiv \pi, \alpha^{1}=\alpha^{2} \equiv \alpha, e^{1}=e^{2} \equiv e$ et $g^{1}=g^{2} \equiv g$ i.e. if the unuque asymmetry is about the scale or market shares of the two groups, the system of equations simplifies as 
follows :

$$
\begin{gathered}
\left(\begin{array}{cc}
e(\gamma+1) & -\pi e(\gamma+1) \\
-\pi e(\gamma+1) & \pi \alpha g(\gamma+1)
\end{array}\right)\left(\begin{array}{c}
p-\beta \\
\bar{p}-\beta
\end{array}\right) \\
=\beta \Phi(\rho)\left(\begin{array}{c}
-\sqrt{\pi(1-\pi)} e \frac{\frac{\gamma^{2}}{N^{1}}+\frac{1}{N^{2}}}{\sqrt{\frac{\gamma^{2}}{N^{1}}+\frac{1}{N^{2}}}} \\
\alpha \sqrt{\pi(1-\pi)} g \frac{\frac{\gamma^{2}}{N^{1}}+\frac{1}{N^{2}}}{\sqrt{\frac{\gamma^{2}}{N^{1}}+\frac{1}{N^{2}}}}
\end{array}\right),
\end{gathered}
$$

from which we obtain :

$$
\underline{p}=\beta \text { et } \bar{p}=\beta+\beta \Phi(\rho) \sqrt{\frac{(1-\pi)}{\pi}} \frac{\sqrt{\frac{\gamma^{2}}{N^{1}}+\frac{1}{N^{2}}}}{(\gamma+1)} .
$$

which could be alternatively expressed as follows, with the parameter $E \equiv \underline{q}^{1}(\underline{p}, \bar{p}) / \underline{q^{2}}(\underline{p}, \bar{p})$ i.e. the ratio of mean consumptions instead of the ratio $\gamma$ of aggregate consumptions between the two groups

$$
\bar{p}=\beta+\beta \Phi(\rho) \sqrt{\frac{(1-\pi)}{\pi}} \frac{\sqrt{N^{1}+(E)^{2} N^{2}}}{N^{1}+E^{2} N^{2}} .
$$

The second-best environment considered here is complicated. Some contingent markets are missing and the impossibility to practice price discrimination among clients adds itself as a second constraint on the regulator. As a consequence of the general second best principle, it may then be optimal to create more distorsions. Then, the derived departures from marginal cost pricing should not come as a surprise.

\subsection{Some Lessons for the Regulation of the Natural Gas Trans- portation Industry}

In this paper, in several occasions, we have pointed out the practical concerns and isues which motivated the theoretical developments on public utility pricing and regulation. We would like to conclude this paper by explaining our personal interest in the market environment developed above.

A marked transformation of the natural gas industry has ocurred all over the world in recent decades towards the liberalization of these markets. According to Doane, McAfee and Williams (2004), in the United States ${ }^{45}$, this process has been primarily facilitated by the

\footnotetext{
${ }^{45}$ The U.S. regulatory policy of natural gas pipelines companies has already been explored by several authors in the sixties and seventies (Callen (1978), MacAvoy and Noll (1973) and Wellisz (1963)). Among other things, under the Natural Gas Act of 1938, the sales to public utilities are treated differently from the industrial sales. The regulation policy calls for an allocation of the overhead cost among these two categories. The behavioral implications on operators of the empirical rule which has been selected to do so (known as the Atlantic Seaboard Formula) has been studied by these authors.
} 
issuance of two orders from the FERC (Federal Energy Regulatory Commission). FERC Order $\mathrm{N}^{\circ} 436$, released in 1985, encouraged pipeline companies to separate their sales and transportation functions; the order also established rules governing open access. FERC Order $\mathrm{N}^{\circ}$ 636, released in 1992, required interstate pipelines to unbundle their gas and transportation functions, to cease selling bundled gas supplies, and to provide comparable transportation to all shippers regardless of whether or not the shipper had also purchased gas from that pipeline. In the European Union, following the 1998 directive, a similar deregulation process ${ }^{46}$ is at works ${ }^{47}$ and unsurprisingly the issues of accounting separation and access to the network of pipelines have also attracted most of the attention of the regulators. Most prominent are the questions of pricing and investment decisions in capacities. While not specific to that industry, the determination of the structure of prices imposed by the regulator to the "authorized" operators in order to get access to the network of pipelines raises some specific difficulties that call for an appropriate analysis.

One of our main concern was to provide a normative framework to evaluate some features of the policy implemented by the French regulator to allocate and price the access to ${ }^{48}$ the existing pipeline capacities across the different firms which have been agreed to deliver natural gas to clients located on the French territory. This policy has many dimensions and we will just examine one aspect of it related to the theoretical framework. Hereafter, we will abusively identify capacity with transportation capacity ("capacité de liaison" in the French terminology) ignoring for the moment, entry, exchange, exit and storage capacities and consider the case of a unique section in the all network ${ }^{49}$. Any operator which want to use this capacity is offered a menu of options. One important aspect of the decision of any operator consists in a capacity reservation : how much daily capacity is "needed" to deliver the natural gas to its clients? Besides the volume part, the operator may opt for annual, monthly or daily reservations. There are some sophisticated rules to allocate sequentially the existing capacities given the reservations which have been made and the (regulated) prices

\footnotetext{
${ }^{46}$ In contrast to the regulatory policy of the United States, no market-based rate proposals submitted by natural gas pipelines is considered at the moment. For an analysis of the theoretical consequences of the role of excess capacity in such regulatory setting, see McAfee and Reny (2006).

${ }^{47}$ The market is active : the growth rate in consumption is about $2 \%$ per year and the total consumption in the European Union was about $493 \mathrm{Gm}^{3}$ in 2005. More figures about the relative weight of this energy in aggregate energy consumption by either residential, commercial or industrial clients, trends for the coming decade and policy statements about the effectiveness of the current regulation can be found e.g. on the web site of the various regulators..

${ }^{48}$ The reader who wish to know more details about the financial and institutionnal aspects of the current system is invited to consult the web sites of the regulator (www.cre.fr) as well as the web site of the public utility which is here the main operator of the network (www.gazdefrance-reseau-transport.com)

${ }^{49}$ We refer the reader to the the annual report of the French regulator for a detailed description of the regulatory process and its evolutions.
} 
differ according to the type of reservation which is selected. An operator may be reluctant to make advance reservations when the consumption of many of its clients exhibits a great votality and may prefer to delay reservation and wait for the exact demand emanating from them. The trade-off between the forward and spot contractual arrangements is the one described in the above theoretical model except for the fact that there are three markets instead of two (without accounting for contracts with the possibility of interruption). The differentials in prices according to the time of reservaton are as follows. The tariff for a monthly subscription is equal to $1 / 8$ of the corresponding tariff for an annual reservation. Similarly, the tariff for a daily reservation is equal to $1 / 20$ of the corresponding tariff for a monthly reservation. In both cases, the price has been increased by $50 \%$ i.e. with our above notations :

$$
\frac{\bar{p}}{\underline{p}}=\frac{3}{2}
$$

It would be interesting to contrast this choice with the optimal prices derived from our theoretical normative approach. This calls for an estimation of the main parameters which appear in these formulas. However, it should be recognized that the all theory is based upon a competitive price-taking behavior of the users of this networks. The current context would suggest that the market is imperfectly competitive and that the regulated access prices to the transportatio network act as costs for operators delivering natural gas to end users. Understanding the consequences of the market power of these operators on final prices is important to derive optimal prices that would accont for these extra distorsions with respect to competitive markets.

\section{References}

Kolm, S.C. (1970) "Service Optimal d'une Demande Variable et Prix de l'Incertitude", Revue Economique, 21, 243-271.

Kolm, S.C. (1971a) Le Service des Masses, CNRS, Dunod.

Baron, D. (1971) "Demand Uncertainty and Imperfect Competition", International Economic Review, 12, 196-208.

Berg, S. and T. Tschirhart (1988), Natural Monopoly Regulation, Cambridge University Press.

Boiteux, M (1951) " La Tarification au Coût Marginal et les Demandes Aléatoires", Cahiers du Séminaire d'Econométrie, 1, 56-69. 
Brown, G. et Johnson M. B. (1969), "Public Utility Pricing and Output under Risk", American Economic Review, 59: 119-28.

Brown, S. and D. Sibley (1986), The Theory of Public Utility Pricing, Cambridge University Press.

Callen, J.L. (1978) "Production, Efficiency, and Welfare in the Natural Gas Transmission Industry", American Economic Review, 68, 311-323.

Carlton, D. (1977), "Peak Load Pricing with Stochastic Demand", American Economic Review, 67: 1006-10.

Carlton, D.W. (1978) "Market Behavior with Demand Uncertainty and Price Inflexibility", American Economic Review, 68, 571-587.

Carlton, D.W. (1979) "Contracts, Price Rigidity and Market Equilibrium", Journal of Political Economy, 87, 1034-1062.

Carlton, D.W. (1991) "The Theory of Market Allocation and its Implications for Marketing and Industrial Organization", Journal of Law and Economics, 34, 231-262.

Chao, H.P. (1983) "Peak Load Pricing and Capacity Planning with Demand and Supply Uncertainty", Bell Journal of Economics, 14, 179-190.

Chao, H et Wilson R. (1987), "Priority Service: Pricing, Investment, and Market Organization", American Economic Review, 77: 899-916.

Coate, S. et Panzar J. (1989), "Public Utility Pricing and Capacity Choice Under Risk: A Rational Expectations Approach", Journal of Regulatory Economics, 1: 305-317.

Commission de Régulation de l'Energie (2006) La Régulation du Marché du Gaz Naturel, Rapport d'Activité.

Crew, M. and P. Kleindorfer (1978) "Reliability and Public Utility pricing", American Economic Review, 68, 31-40.

Dana, J.D. (1998) "Advance-Purchase Discounts and Price Descrimination in Competitive Markets", Journal of Political Economy, 106, 395-422.

Dana, J.D. (1999) "Equilibrium Price Dispersion under Demand Uncertainty : the Roles of Costly Capacity and Market Structure", Rand Journal of Economics, 30, 632-660.

Dana, J.D. (2001) "Monopoly Price Dispersion under Demand Uncertainty", International Economic Review, 42, .

David, L. Le Breton, M. and O. Merillon (2007a) "Regulating the Natural Gas Transportation Industry : Optimal Pricing Policy of a Monopolist with Advance-Purchase and Spot markets", Mimeo.

David, L. Le Breton, M. and O. Merillon (2007b) "Kolm as a Contributor to Public Utility Pricing, Second Best Culture and the Theory of Regulation", Mimeo. 
Deneckere, R. and J. Peck (1995) "Competition over Price and Service Rate when Demand is Stochastic : a Strategic Analysis", Rand Journal of Economics, 26, 148-162.

Diamond, P. (1980) "Efficiency and Uncertain Supply", Review of Economic Studies, 47, 645-651.

Doane, M.J., McAfee, P.R. and M.A. Williams (2004) "Evaluating and Enhancing Competition in the Interstate Natural Gas Transportation Industry", Natural Resources Journal, 44,761-808.

Drèze, J.H. (1964) "Some Postwar Contributions of French Economists to Theory and Public Policy : with Special Emphasis on Problems of Resource Allocation", American Economic Review, 54, 1-64.

Drèze, J.H. (1995) "Forty Years of Public Economics : A personal Perspective", Journal of Economic Perspectives, 9, 111-130.

De la Vallée Poussin, D. (1968) "Tarification de l'Electricité selon la Moyenne et la Variance de la Consommation Individuelle", Recherches Economiques de Louvain, 34, 53-72.

Eden, B. (1990) "Marginal Cost pricing when Spot Markets are Complete", Journal of Political Economy, 1293-1306.

Energy and Environmental Economics, Inc (2006) A Survey of Time-of-Use (TOU) Pricing and Demand-Response (DR) Programs.

Gale, I.L. and T.J. Holmes (1992) "The Efficiency of Advance Purchase Discounts in the Presence of Aggregate Demand Uncertainty", International Journal of Industrial Organization, 10, 413-437.

Gale, I.L. and T.J. Holmes (1993) "Advance Purchase Discounts and Monopoly Allocation of Capacity", American Economic Review, 83, 135-14.

Granovetter, M., Mc Guire, P. and V. Yakubovich (2005) "Electric Charges : The social Construction of Rate Systems", Theory and Society, 34, 579-612.

Green, J.R., Mas-Colell, A. and M.D. Whinston (1995), Microeconomic Theory, Oxford University Press.

Marchand, M. (1974) "Pricing Power Supplied on an Interruptible Basis", European Economic Review, 5, 263-274.

McAfee, P.R. and P.J. Reny (2006) "The Role of Excess Capacity in Determining Market Power in Natural Gas Transportation Markets", Caltech, Mimeo.

McAfee, P.R., Doane, M.J., Nayyar, A. and M.A. Williams " (2006) "Interpretating Concentration Indices in the secundary Market for Natural Gas Transportation : The Implication of Pipeline Residual Rights", Caltech, Mimeo.

McAvoy, P.W. and R. Noll (1973) "Relative Prices on Regulated Transactions of the 
Natural Gas Pipelines", Bell Journal of Economics, 4, 212-234.

Meyer, R. (1975), "Monopoly Pricing and Capacity Choice Under Uncertainty", American Economic Review, 65: 326-37.

Oren, S., Smith, S. and R. Wilson (1985) "Capacity Pricing", Econometrica, 53, 545-566.

Panzar, J. and D. Sibley (1978) "Public Utility Pricing under Risk : the Case of SelfRationing", American Economic Review, 68, 888-895.

Polemarchakis, H.M. (1979) "Incomplete Markets, Price Regulation and Welfare", American Economic Review, 69, 662-669.

Prescott, E.C. (1976) "Efficiency of the Natural Rate", Journal of Political Economy, 83, 1229-1236.

Rees, R. (1980), "Consumer Choice and Nonprice Rationing in Public Utility Pricing", in Proceedings of an International Symposium on Public Regulation and Public Enterprises, P.Kleindorfer and B. Mitchell (Eds), Lexington, MA: D.C. Heath.

Seeto, D.Q., Woo, C.K. and I. Horowitz (1997) "Time-of Use rates vs Hopkinson Tariffs Redux: An analysis of the Choice of Rate Structures in a Regulated Electricity Distribution Company", Energy Economics, 19, 169-185

Sherman, R. and M. Visscher (1978) "Second Best Pricing with Stochastic Demand", American Economic Review, 68, 41-53.

Spulber, D.F. (1992a) "Capacity-Contingent Nonlinear Pricing by Regulated Firms", Journal of Regulatory Economics, 4, 299-319.

Spulber, D.F. (1992b) "Optimal Nonlinear Pricing and Contingent Contracts", International Economic Review, 33, 747-772.

Stigler, G.J. (1940) "Round table on Cost Functions and their Relations to Imperfect Competition", American Economic Review, 30, 400-402.

Turvey, R. (1970) "Public Utility Pricing and Output under Risk: Comment", American Economic Review, 60: 485-86.

Veall, M.R. (1983) "Industrial Electricity Demand and the Hopkinson rate : An Application of the Extreme value Distribution", Bell Journal of Economics, 14, 427-440.

Visscher, M. (1973), "Welfare-Maximizing Price and Output with Stochastic Demand: Comment", American Economic Review, 63: 224-229.

Wellisz, S.H. (1963) "Regulation of Natural Gas Pipeline Companies : An Economic Analysis", Journal of Political Economy, 71, 30-43.

Wilson, C.A. (1988) "On the Optimal Pricing of a Monopolist", Journal of Political Economy, 96, 164-176..

Wilson, R. (1991), Nonlinear Pricing, Oxford University Press 
Woo, C.K., Orans, R., Horii, B. and P. Chow (1995) "Pareto-Superior Time-of Use Rate Option for Industrial Firms", Economic Letters, 49, 267-272.

Woo, C.K., Chow, P. and I. Horowitz (1996) "Optional real-Time pricing of Electricity for Industrial Firms", Pacific Economic Review, 1, 79-92.

Woo, C.K., Horii, B. and I. Horowitz (2002) "The Hopkinson Tariff Alternative to TOU Rates in the Israel Electric Corporation", Managerial and Decision Economics, 23, 9-19. 